University of Wollongong

Research Online

Faculty of Engineering and Information

Faculty of Engineering and Information

Sciences - Papers: Part B

Sciences

2019

The development and ballistic performance of protective steel-concrete composite barriers against hypervelocity impacts by explosively formed projectiles

\author{
Alex M. Remennikov \\ University of Wollongong, alexrem@uow.edu.au \\ Edward Gan \\ University of Wollongong, ecjg428@uowmail.edu.au \\ Tuan D. Ngo \\ University of Melbourne \\ Michael Netherton \\ University of Newcastle
}

Follow this and additional works at: https://ro.uow.edu.au/eispapers1

Part of the Engineering Commons, and the Science and Technology Studies Commons

Research Online is the open access institutional repository for the University of Wollongong. For further information contact the UOW Library: research-pubs@uow.edu.au 


\title{
The development and ballistic performance of protective steel-concrete composite barriers against hypervelocity impacts by explosively formed projectiles
}

\author{
Abstract \\ Explosively formed projectiles (EFP) are one of the most severe explosive and impact loading threats for \\ civil infrastructure and military vehicles. Currently, there is no effective means of protection for military \\ vehicles and infrastructure facilities from EFPs. This paper presents the experimental results of the \\ hypervelocity impact of EFPs on steel-concrete (SC) barrier systems of finite dimensions. The SC barrier \\ units tested were broadly representative of the type of protective SC units used in the expedient \\ construction of barriers for mitigating improvised explosive device (IED) and EFP threats to critical \\ infrastructure facilities. The response of non-composite, partially-composite, and fully-composite SC \\ barrier units was studied. All studied protective systems were capable of terminating the high-velocity \\ projectiles effectively through the combined action of the concrete core and steel faceplates. The data \\ gathered from these tests are also intended to further the understanding of impacts on SC composite \\ structures at speeds greater than $1000 \mathrm{~m} / \mathrm{s}$ and for the calibration of numerical models of EFP interaction \\ with SC targets. 3D numerical simulations were performed to better understand the various stages of EFP \\ interaction with the SC composite barriers and develop recommendations for their design optimisation. \\ No previously published results on the EFP terminal ballistic performance of SC composite structures of \\ finite dimensions have been found in the open literature. \\ Disciplines \\ Engineering | Science and Technology Studies

\section{Publication Details} \\ Remennikov, A., Gan, E. C. J., Ngo, T. \& Netherton, M. D. (2019). The development and ballistic \\ performance of protective steel-concrete composite barriers against hypervelocity impacts by explosively \\ formed projectiles. Composite Structures, 207 625-644.
}

This journal article is available at Research Online: https://ro.uow.edu.au/eispapers1/1837 


\title{
THE DEVELOPMENT AND BALLISTIC PERFORMANCE OF PROTECTIVE STEEL-CONCRETE COMPOSITE BARRIERS AGAINST HYPERVELOCITY IMPACTS BY EXPLOSIVELY FORMED PROJECTILES
}

\author{
Alex Remennikov*1, Edward C. J. Gan ${ }^{2}$, Tuan $\mathrm{Ngo}^{3}$, and Michael D. Netherton ${ }^{4}$ \\ ${ }^{1}$ Centre for Infrastructure Protection and Mining Safety, University of Wollongong, \\ Wollongong, NSW 2522, Australia, e-mail: alexrem@uow.edu.au \\ ${ }^{2}$ Faculty of Engineering and Information Sciences, University of Wollongong, \\ Wollongong, NSW 2522, Australia, e-mail: ecjg428@uowmail.edu.au \\ ${ }^{3}$ Department of Infrastructure Engineering, The University of Melbourne, Parkville, \\ VIC, 3010, Australia, e-mail: dtngo@unimelb.edu.au \\ ${ }^{4}$ Centre for Infrastructure Performance and Reliability, The University of Newcastle. \\ Callaghan, NSW 2308, Australia, e-mail: michael.netherton@newcastle.edu.au
}

\section{Abstract}

Explosively formed projectile (EFP) is one of the most severe explosive and impact loading threats for civil infrastructure and military vehicles. Currently, there is no effective means of protection for military vehicles and infrastructure facilities from EFPs. This paper presents the experimental results of the hypervelocity impact of EFPs on steel-concrete (SC) barrier systems of finite dimensions. The SC barrier units tested were broadly representative of the type of protective SC units used in the expedient construction of barriers for mitigating improvised explosive device (IED) and EFP threats to critical infrastructure facilities. The response of non-composite, partially-composite and fully-composite SC barrier units was studied. All studied protective systems were capable of terminating the high-velocity projectiles effectively through the combined action of the concrete core and steel faceplates. The data gathered from these tests is also intended to further the understanding of impacts on SC composite structures at speeds greater than $1000 \mathrm{~m} / \mathrm{s}$ and for the calibration of numerical models of EFP formation and its interaction with steel-concrete targets. 3D numerical simulations were performed to better understand the various stages of EFP interaction with the SC composite barriers and develop recommendations for their design optimisation. No previously published results on the EFP terminal ballistic performance of SC composite structures of finite dimensions have been found in the open literature.

Keywords: Explosively formed projectiles, hypervelocity impact, steel-concrete protective structures, terminal ballistic 


\section{INTRODUCTION}

40 Improvised explosive devices (IEDs) present a significant challenge to conventional 41 armour systems and civil engineering infrastructure. One type of IED that has been particularly difficult to defeat using conventional protective measures is known as explosively formed projectiles (or EFPs). EFP warheads are commonly found in 44 conventional anti-tank weapons. They are also regularly used by insurgent forces against armoured vehicles in conflict-affected countries. The energy of EFPs is significantly greater than that of large calibre ammunition, such that a threat is posed to the occupants of armoured vehicles both by perforation and spalling of the armour.

One such EFP device is schematically illustrated in Figure 1, wherein a high 49 explosive is placed in a tube holder having an open end. A dish-shaped metallic 50 liner, typically copper, is placed at the open end with its concave surface facing 51 outward, so that the high explosive is enclosed within the tube behind the metallic liner. This improvised device is positioned so that the concave surface of the copper dish faces the target. When detonated, the explosive shock wave hits the liner at the apex first and the high pressure remains there longer than around the rim where the detonation front arrives later [1]. This turns the liner into an essentially super-plastic shape by turning it inside out and driving it forward with the apex in front until the entire disc has folded in on itself to form a slug. The final geometry of the slug (Figure 1) is determined by stretching and collapse deformation modes caused by a combination of higher velocity of the liner elements near the axis and initial curvature of the liner. 


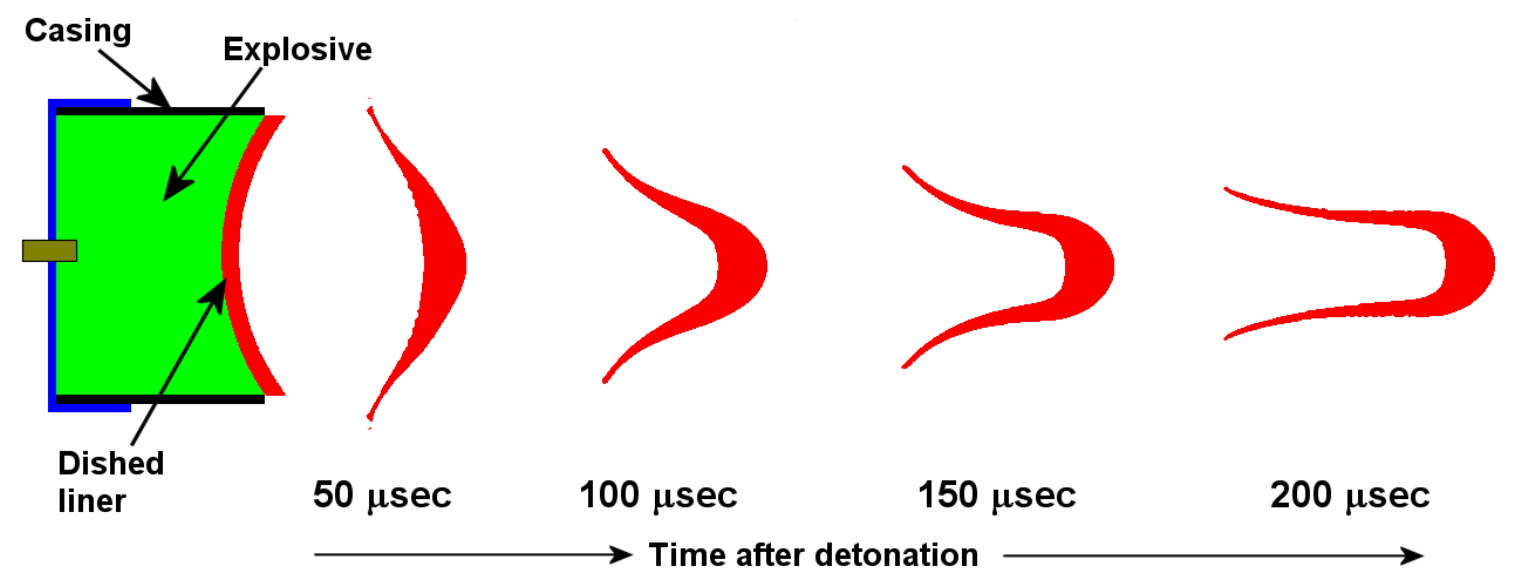

60

61

62

63

64

65

66

67

68

69

\section{Figure 1: Formation of an explosively formed projectile (EFP)}

Relatively limited research has been published in the open literature on defeating this threat [2]. Instead, the bulk of research has been focused on investigating the protection of armour against conventional shaped charges and long-rod penetrators, which are very different in their penetration mechanics to an EFP. Existing publications in the area of EFPs predominantly addressed performance and penetration of steel armoured solutions with a direct application to the protection of armoured vehicles such as armoured fighting vehicles and infantry mobility vehicles.

The resistance of conventional structural components to hypervelocity impacts by EFPs has not been previously studied systematically and is not a well understood phenomenon.

Some recent work describing the flight, and destructive capabilities of EFP experimentally and numerically have been noted. For example, Wu et al. [3] numerically simulated the entire process of slug formation, flight and the penetration of a $60 \mathrm{~mm}$ calibre EFP on a $25 \mathrm{~mm}$ steel target. It was found that the projectile was able to easily penetrate the steel target before breaking into chips and bursting away. Liu et al. [4] studied ballistic performance of monolithic and composite structures including three-layered in-contact and spaced mild steel targets and found that the multi-layered targets with the thinner sub-structures in front and thicker sub-structures at back are 
80 superior to resist the penetration of the copper EFP. Hu et al. [5] assessed the impact 81 performance of EFP on concrete targets. Various EFP parameters (e.g. liner and explosive materials) were evaluated and it was concluded that the configuration with a copper liner and Composition $\mathrm{B}$ explosive resulted in maximum penetration into 84 concrete.

Figure 2 shows the reinforced concrete walls breached by a $300 \mathrm{~mm}$ diameter EFP demolition device [6]. The EFP breached the first two concrete wall targets and had sufficient energy to topple a third wall (not shown). Bookout and Baird [7] conducted an extensive experimental program on unreinforced concrete targets of $600 \mathrm{~mm}$ thickness impacted by a $100 \mathrm{~mm}$ calibre EFP. Their experimental results demonstrate that an EFP

90 is capable of destroying and penetrating substantial unreinforced and reinforced concrete targets.

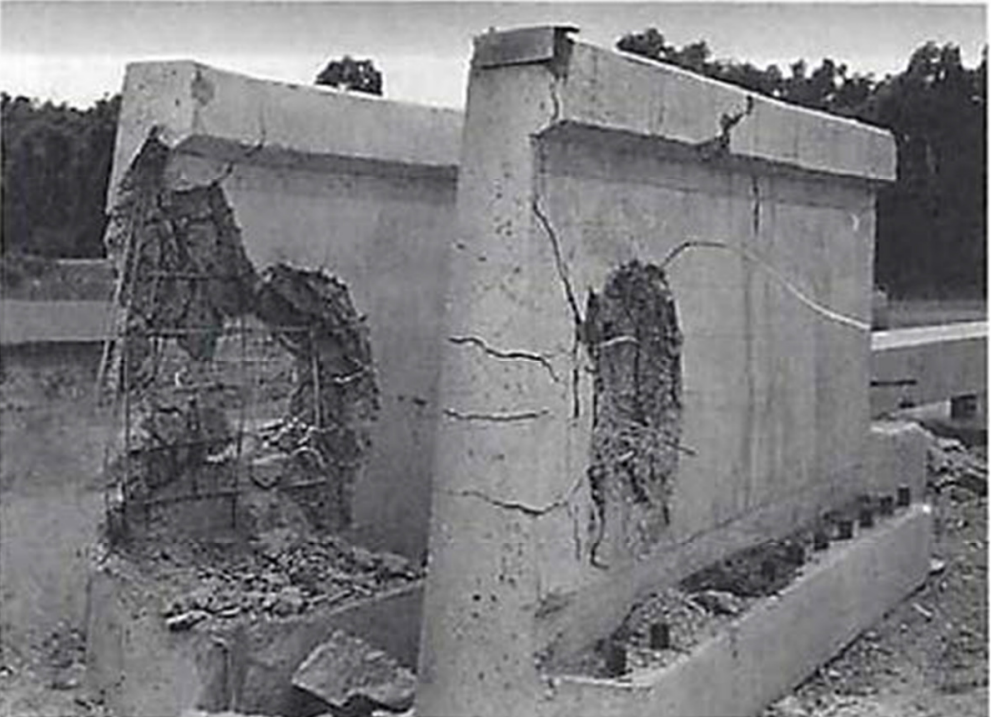

Figure 2: Destructive force of EFP experienced by reinforced concrete wall targets [6]

Steel-concrete protective structural solutions are common in nuclear installations as the primary containment system for some reactor types. Bruhl et al. [8] proposed a threestep method for designing steel plate composite (SC) walls subjected to missile impact. This method can be used to compute the minimum required steel plate thickness for SC walls to prevent perforation from missile threats with initial velocities between $20 \mathrm{~m} / \mathrm{s}$ and $230 \mathrm{~m} / \mathrm{s}$, 
99 and missile weights up to around $2000 \mathrm{~kg}$. For parameters outside of this range, the

100 validated finite element analysis approach is recommended for conservative evaluation.

101 Hashimoto et al. [9] carried out an experimental study on the behaviour of RC panels

102 reinforced with steel plates subjected to missile impact as part of a project on designing

103 nuclear-related facilities for extreme loading conditions such as an accidental aircraft crash

104 or terrorist attack. In their experiments, the missile velocities were in the range of $140 \mathrm{~m} / \mathrm{s}$ to

$105270 \mathrm{~m} / \mathrm{s}$. One of the main findings of this study was that a concrete panel with a steel plate

106 on its rear face had higher impact resistance than a reinforced concrete panel. When used on

107 the front face of a concrete panel, a steel plate was less effective compared to the concrete

108 panels with steel cladding on the rear side.

109 Performance of steel tubular structures and panels filled with concrete as protective

110 structures have been studied by Remennikov et al. [10, 11]. Remennikov and Uy [10]

111 experimentally investigated the failure modes of concrete-filled steel tubular elements due

112 to contact and near-field detonation of TNT charges. Remennikov et al. [11] carried out an

113 investigation into the response of axially restrained non-composite steel-concrete-steel

114 (SCS) sandwich panels subjected to blast and impact loads, and demonstrated the high

115 effectiveness of steel-concrete sandwich panels as protective barriers against high-speed

116 vehicle impacts and close-range blasts. Ngo et al [12] carried out a comprehensive, non-

117 linear three-dimensional numerical analysis the concrete-filled square tubular columns

118 subjected to blast loading due to close range detonation of the TNT charges and

119 highlighted the beneficial effect of concrete as an infill material in protective composite 120 structures.

121 The performance of steel-concrete structural elements has been extensively studied

122 experimentally, analytically and numerically for high-speed vehicle impacts, as well as far-

123 field and near-field high explosive (HE) detonations and contact charge detonations. 
124 However, the performance of concrete structures cladded with steel face plates when

125 subjected to hypervelocity impacts in excess of $1000 \mathrm{~m} / \mathrm{s}$ produced by such IED threats

126 similar to EFPs is uncertain. This study investigates the possibility of utilising concrete units

127 cladded with steel face plates for infrastructure protection against EFPs. The presented

128 experimental program includes EFP testing of steel-concrete protective systems with

129 different construction types to evaluate their effectiveness in mitigating IED-EFP threats to

130 built infrastructure. The experimental results are subsequently used for calibrating

131 numerical models of EFP penetration into the steel-concrete protective barriers.

\section{EXPERIMENTAL SETUP AND TEST PROGRAM}

133 The EFP device design was based on the recommended empirical design parameters for

134 the explosively formed projectiles $[1,6]$. The EFP consisted of carbon fibre-reinforced

135 polymer (CFRP) casing and a copper liner as shown in Figure 3. CFRP was used for

136 the casing to provide a high level of confinement while having a lower likelihood of

137 generating safety hazards due to fragmentation than steel casing. The CFRP casing was

138 manually packed with the Composition B explosive (60/40 mixture of RDX and TNT,

139 density: $1600 \mathrm{~kg} / \mathrm{m}^{3}$, detonation velocity: $8,050 \mathrm{~m} / \mathrm{s}$ ) and closed from one end with the

140 plastic end cap. At the other end of the CFRP tube, the copper liner was placed so as

141 to ensure an intimate contact with the high explosive fill. An electric detonator was

142 inserted through the plastic cap into the explosive fill and used for initiating the EFP

143 device. 


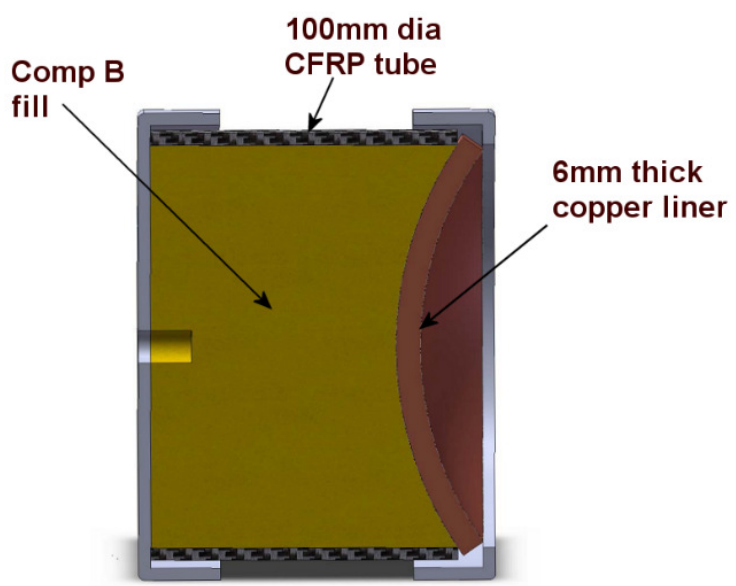

\section{Figure 3: Schematic view of an EFP device}

The steel-concrete targets were tested in the blast trial range facility shown in Figure 4(a). The distance between the firing position of the EFP devices and the targets was 6 meters. Previous studies of the EFP formation [1] have shown that the complete development of the EFP requires less than $400 \mu \mathrm{s}$, which means that the selected distance between the firing position and the target is acceptable. A $1.5 \mathrm{~m} \times 2.5 \mathrm{~m}$ board with black and white stripes was positioned between the firing position and the targets to assist with the measurements of the projectile velocity with a high-speed camera, which was positioned in front of the board and perpendicular to the projectile's flight path. Figure 4(b) demonstrates the installed EFP device prior to testing. The welded steel tubular adjustable mounts were used for precisely positioning and targeting the devices.

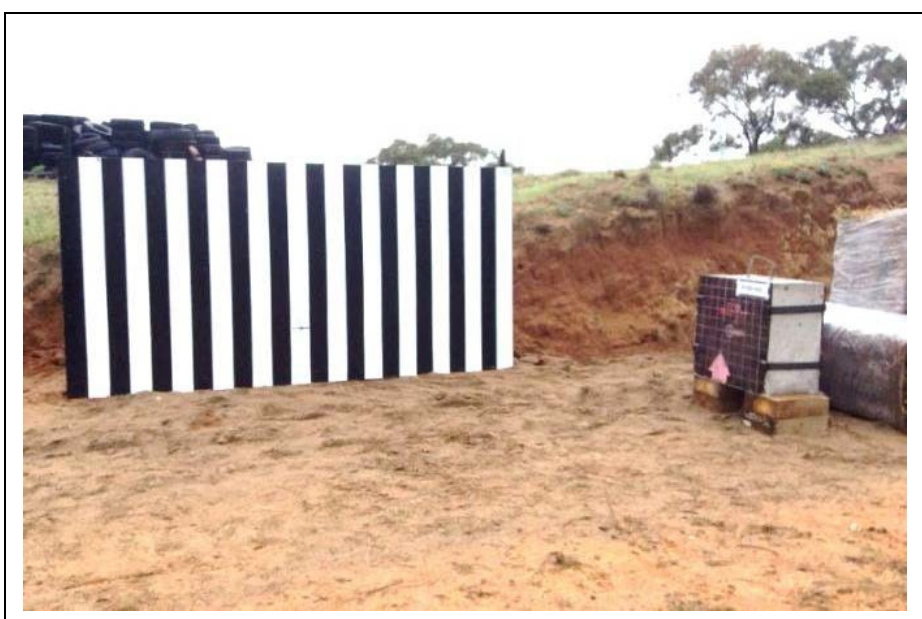

(a)

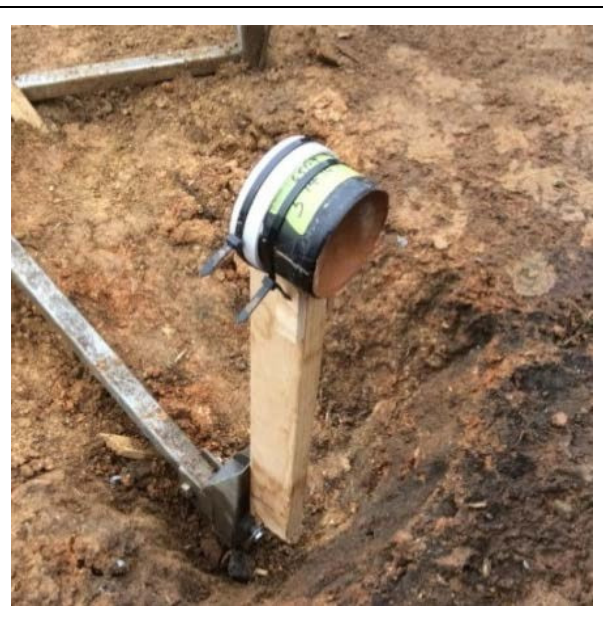

(b)

Figure 4: Experimental setup for: (a) EFP testing of targets and measurement of the velocity of high-speed projectiles; (b) EFP device installation prior to firing 
160 consisted of front and rear steel face plates, and a concrete core. Three groups of SC units

161 were constructed to develop a better understanding of the effects of concrete strength,

162 strength of the steel face plates, and the connection or "composite action" between the

163 concrete core and the steel face plates. The test matrix, unit IDs and material properties of

164 the steel faceplates and the concrete cores are detailed in Table 1. In Table 1, BISXX

165 refers to a high-strength steel plate of Grade XX manufactured by Bisalloy Steels in

166 Australia [13], and NSC and HSC refer to normal- and high-strength concrete,

167 respectively.

168 The first group of SC units included a baseline design BIS400-NSC-150, which 169 consisted of an NSC concrete core with a compressive strength of $42 \mathrm{MPa}$ and the high170 strength steel face plates. The face plates and the core were not mechanically connected 171 apart from the chemical bond developed between the steel and concrete during the curing 172 process. The concrete core of BIS400-NSC-150 was not reinforced. The SC unit BIS500173 NSC-REO also did not have the steel plates connected to the core but its concrete core 174 was reinforced with steel meshes and shear links. This type of SC unit was expected to 175 demonstrate the effectiveness of steel lining and reinforcing the concrete core. Since no 176 connectors were used in this protective system design, we will refer to it as "non177 composite" in this paper.

178 The second group of SC units addressed several parameters such as concrete strength, 179 steel strength and the effect of tying the steel face plates internally and externally. This 180 group included six test unit designs, namely BIS80-NSC, BIS80-HSC, BIS400-NSC, 181 BIS400-HSC, BISHH-NSC and BISHH-HSC. Two concrete mix designs were used for 182 filling the sandwich block to yield normal strength concrete and high strength concrete 183 cores. The front and rear steel plates were connected with three internally welded ties bars 
184 with a dimeter $8 \mathrm{~mm}$ for holding the steel plates in place during concrete pour.

185 Additionally, in some designs the externally welded steel straps were used to introduce

186 some degree of composite action between the steel plates and the concrete core. As such,

187 this group of protective units is referred to as "partially composite" in Table 1 and in the

188 remainder of this paper.

189 The third group of SC units addressed the effect of fully restraining the steel face

190 plates against outward motion caused by high-intensity stress waves propagating through

191 the layered media (steel-concrete-steel). Units of BIS500-NSC-BOLTS were designed

192 with four high-strength bolts of $16 \mathrm{~mm}$ diameter through the thickness of the block. This

193 group is referred to as "fully composite" to reflect that this design provides a strong

194 mechanical connection between the steel face plates and the concrete core.

195

196 Table 1: Test matrix and properties of steel and concrete components of barrier units

\begin{tabular}{lcccccc}
\hline & \multicolumn{2}{c}{ Steel face plates } & \multicolumn{3}{c}{ Concrete core } & Connection \\
\cline { 2 - 6 } Unit ID & $\begin{array}{c}\text { Thickness } \\
{[\mathbf{m m}]}\end{array}$ & $\begin{array}{c}\text { Yield } \\
\text { strength } \\
{[\mathbf{M P a}]}\end{array}$ & $\begin{array}{c}\text { Thickness } \\
{[\mathbf{m m}]}\end{array}$ & $\begin{array}{c}\text { Compressive } \\
\text { strength } \\
{[\mathbf{M P a}]}\end{array}$ & $\begin{array}{c}\text { Reinforce- } \\
\text { ment }\end{array}$ & $\begin{array}{c}\text { between core } \\
\text { and plates }\end{array}$ \\
\hline BIS400-NSC-150 & 9.5 & 1320 & 150 & 42 & No & Chemical bond \\
BIS80-NSC & 9.5 & 830 & 300 & 40 & No & Ties and straps \\
BIS80-HSC & 9.5 & 830 & 300 & 75 & No & Ties and straps \\
BIS400-NSC & 9.5 & 1320 & 300 & 40 & No & Ties and straps \\
BIS400-HSC & 9.5 & 1320 & 300 & 75 & No & Ties and straps \\
BISHH-NSC & 9.5 & 1640 & 300 & 40 & No & Ties and straps \\
BISHH-HSC & 9.5 & 1640 & 300 & 75 & No & Ties and straps \\
BIS500-NSC-BOLTS & 9.5 & 1400 & 300 & 42 & No & HS through bolts \\
BIS500-NSC-REO & 9.5 & 1400 & 300 & 42 & 10 mm bars & Chemical bond \\
& & & & & @ 100 mm & mesh both \\
\end{tabular}

197

198

1993 MOTION ANALYSIS OF EFP PROJECTILES

200 The velocity of the projectiles was estimated using motion analysis of the high-speed video 
201 footage recorded during the EFP firings. The velocity of the projectile significantly affects

202 the projectile's ability to penetrate a target due to the squared velocity value in the kinetic

203 energy equation. In this experimental program, the velocity tests used a Memrecam HX-3

204 high-speed camera to collect video recordings of the projectile's path. The Memrecam HX-3

205 high-speed camera was set to 25,000 frames per second (fps). The black and white striped

206 Zebra board was placed 3.0 meters away from the firing position and parallel to the

207 projectile's path. The black and white stripes were $100 \mathrm{~mm}$ wide.

208 Figure 5 shows a typical snapshot where the flying EFP could be clearly identified as

209 it was passing a white stripe of the Zebra board. By tracking the flight of the projectile over

210 several frames recorded every 40 microseconds, the velocity of the EFP was calculated. The

211 average projectile velocities are summarised in Table 2. These average velocities are

212 comparable with the similar EFP design described in [7] where a velocity of $1317 \mathrm{~m} / \mathrm{s}$ was

213 determined using C-4 explosive fill.

214

Table 2: Summary of EFP parameters and calculated velocities

\begin{tabular}{lccc}
\hline \multicolumn{1}{c}{ Group of SC blocks } & $\begin{array}{c}\text { Ave. explosive } \\
\text { fill mass [g] }\end{array}$ & $\begin{array}{c}\text { Ave. mass of } \\
\text { copper disk [g] }\end{array}$ & $\begin{array}{c}\text { Ave. EFP } \\
\text { velocity [m/s] }\end{array}$ \\
\hline \#1 ("non-composite" blocks) & 1380 & 460 & 1228 \\
\#2 ("partially composite" blocks) & 850 & 536 & 1198 \\
\#3 ("fully composite" blocks) & 1358 & 460 & 1215 \\
\hline
\end{tabular}




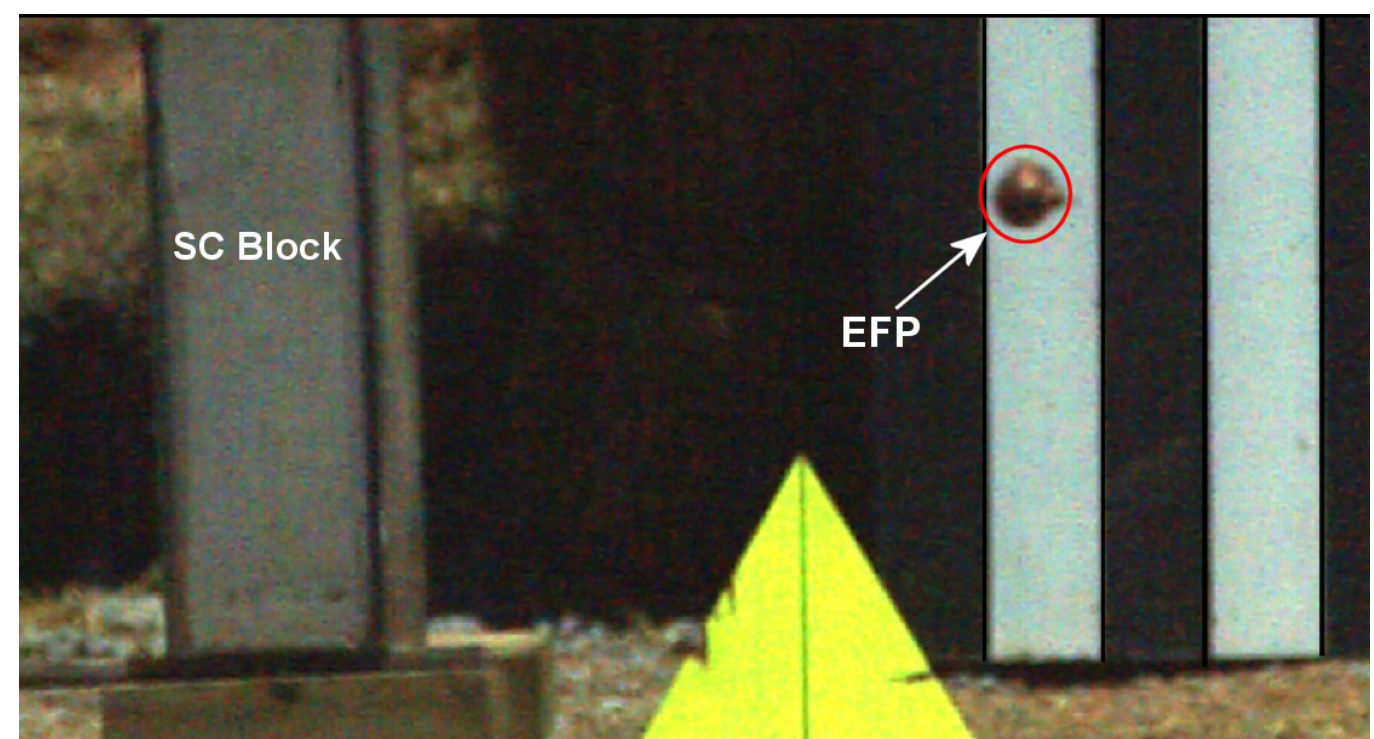

218 The soft recovery system was developed to capture the projectiles in the tests without

219 the targets. Based on previous experience with capturing similar EFP slugs, the soft

220 recovery system utilised 12 hay bales placed behind the targets as shown in Figure 6(a),

221 followed by the sand section. One of the recovered projectiles is shown in Figure 6(b).

222 The recovered projectile has an air cavity that begins at the tail and progresses forward

223 into the projectile, which is difficult to observe. The presence of the air cavity confirms that

224 the slug did not collapse completely during the formation process as shown in Figure 1.

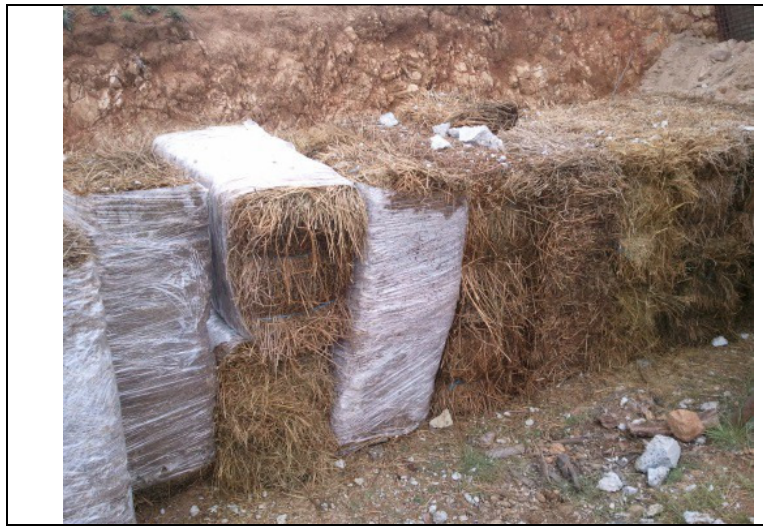

(a)

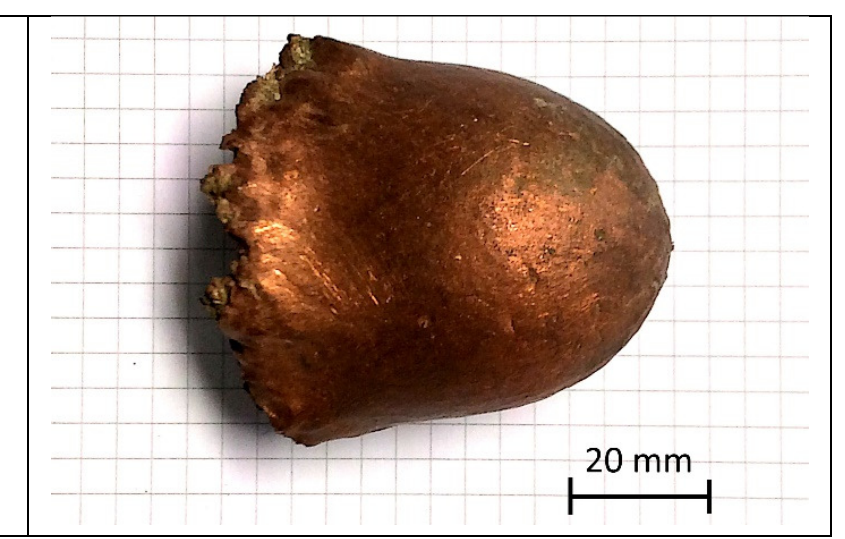

(b)

Figure 6: (a) soft recovery system; (b) recovered slug 


\section{PERFORMANCE OF STEEL-CONCRETE (SC) PROTECTIVE SYSTEMS}

\subsection{Performance of SC Unit with Unreinforced Core and Unrestrained Face Plates}

230 The resistance of SC units with unrestrained faceplates to hypervelocity impacts by the EFPs

231 was investigated first. As mentioned previously, the face plates were connected to the

232 concrete core only through the chemical bond developed during the curing process. The

233 target unit BIS400-NSC-150 is shown in Figure 7(a).

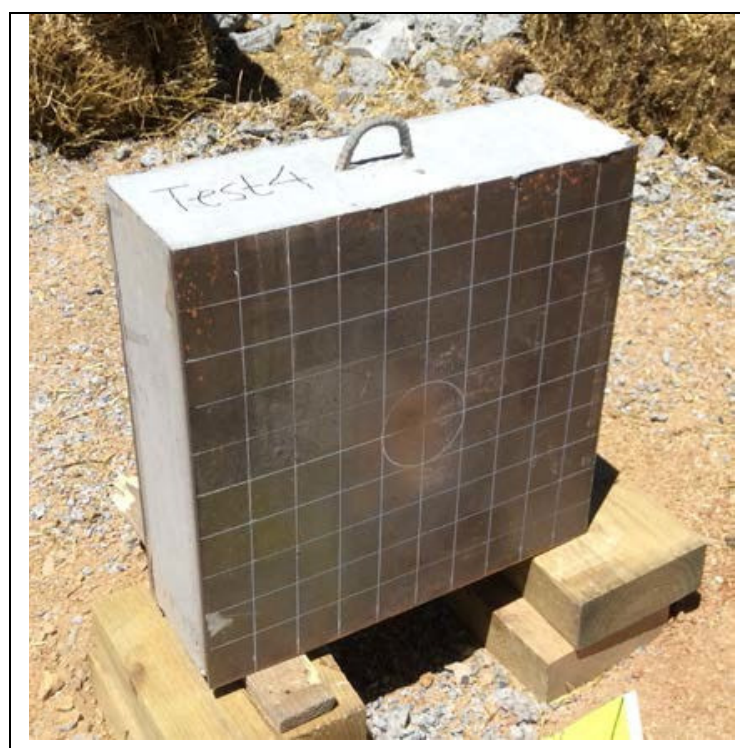

(a)

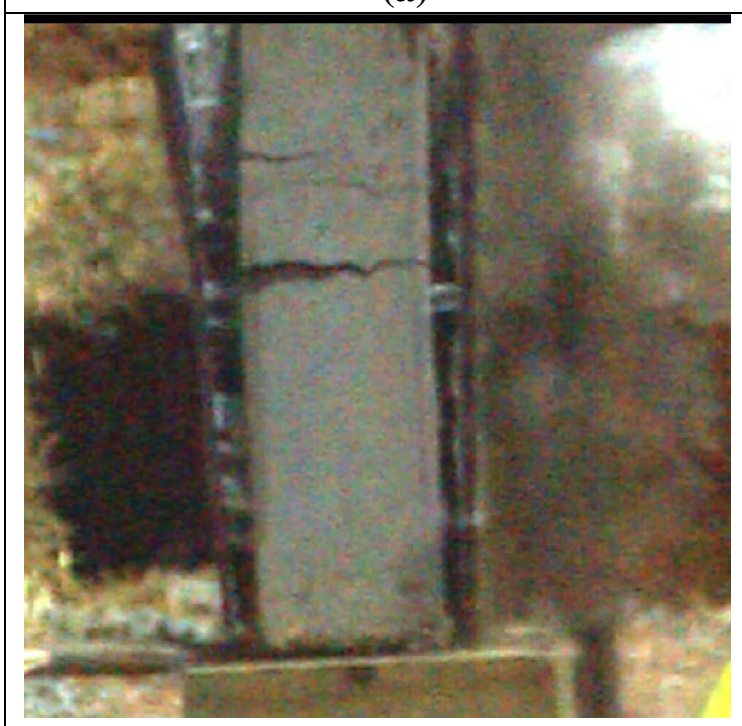

(c)

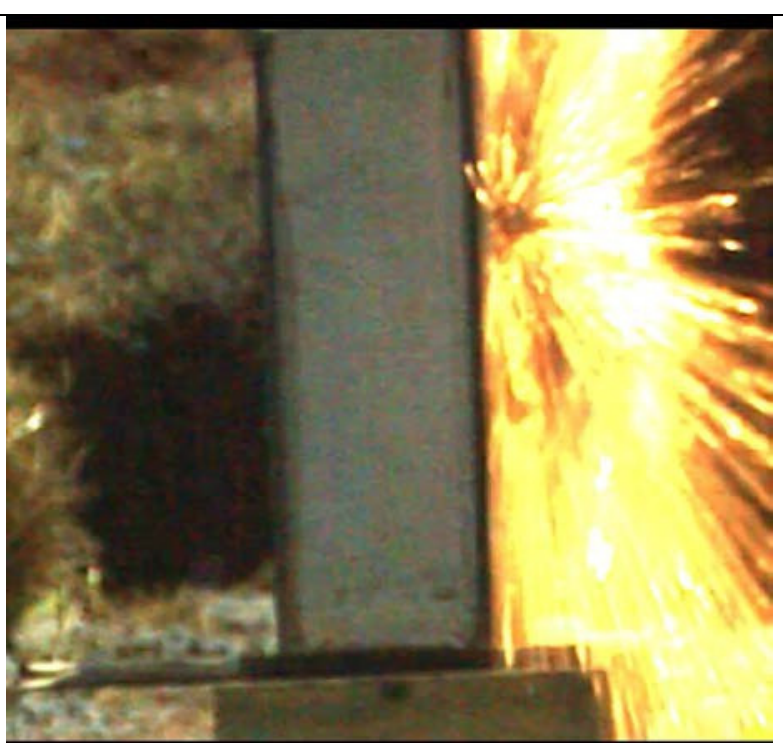

(b)

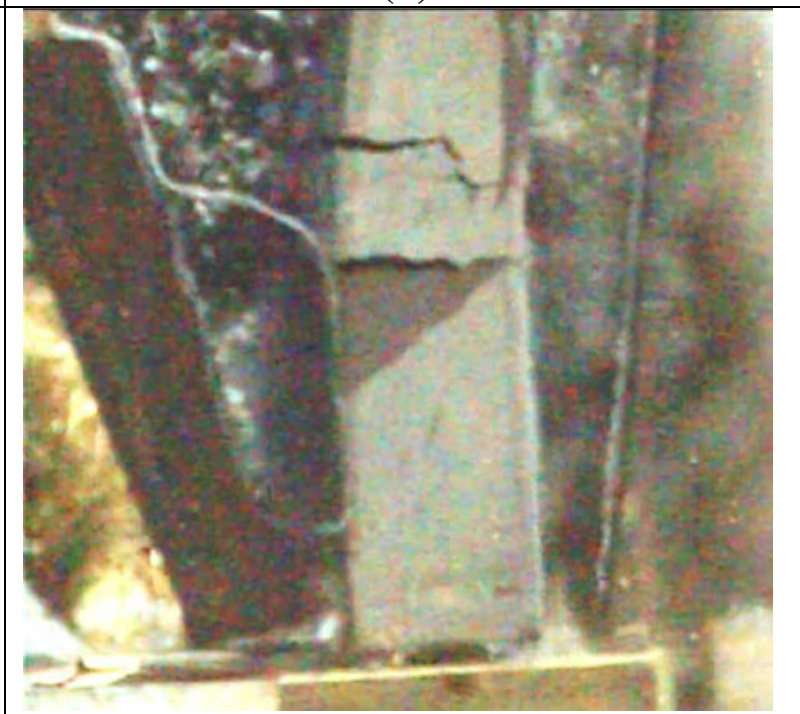

(d)

Figure 7: Target unit BIS400-NSC-150: (a) view before impact; (b) initial contact between the copper projectile and front steel plate; (c) initial horizontal crack in the concrete; (d) separation of the front and rear steel plates 
The target unit was subjected to a hypervelocity impact by a projectile flying with a velocity of $1200 \mathrm{~m} / \mathrm{s}$. The high-speed impact of a copper projectile into a front steel plate results in localised melting of both metals and increased luminosity as depicted in Figure 7(b). Figure 7(c) demonstrates an initial response of the target unit where the steel faceplates start moving away from the concrete core and the concrete core develops a large crack in the central horizontal plane.

The outward motion and separation of the steel face plates can be explained by complex interactions between the compressive and release stress waves at the interfaces between the concrete core and the steel plates. As Figure 7(d) depicts, failure of the BIS400NSC-150 unit resulted in fragmentation of the concrete core into large projectiles flying with a high velocity, which are capable of inflicting secondary damage in the protected targets. Despite severe damage of the SC protective unit with unrestrained steel face plates, the EFP did not penetrate into the rear steel plate thereby indicating that it was fully arrested by the $150 \mathrm{~mm}$ thick concrete core. Based on the experimental observations, the SC blocks with

251 the mechanically unrestrained liners can be used as protective barriers against EFPs but their

252 failure response might produce large steel and concrete projectiles, as well as associated secondary fragmentation hazards to the protected targets.

The subsequent sections in this paper will present the options for improving the overall performance of the SC protective units as protective barriers against explosively formed projectiles.

\subsection{Performance of SC Unit with Unreinforced Core and Partially Restrained}

\section{Face Plates}

259 High-speed cameras were used to record the ballistic response of the steel-concrete 260 protective systems. Images obtained from high-speed video recordings were helpful in

261 diagnosing the damage sequence of the target elements as well as any experimental 
anomalies. Several frames from the high-speed recordings, marked by an approximate

263 time after impact, are shown in Figure 8. Figure 8(a) shows an EFP just prior to

264 impacting on the front steel plate. The increased luminosity at $0.60 \mathrm{~ms}$ (Figure 8(b)) is

265 due to impact of the projectile on the steel plate and melting of the metals in the impact

266 zone.

267 By the approximate time of $1.0 \mathrm{~ms}$ after impact, the concrete core experienced

268 severe shear cracking originating from the front surface of the concrete core at the point

269 of impact and propagating through the entire thickness of the concrete core. Figure 8(c)

270 also shows that the front steel plate receives the impulse in the direction opposite to the

271 direction of impact, which results in fracture at the connections between the steel welded

272 straps that were holding the steel plates and the concrete core together, and the front steel

273 plate. After the tensile fracture of the steel welded straps, the front steel plate starts

274 moving away from the concrete core that also continues to shatter into multiple fragments

275 of concrete as shown in Figure 8(d).

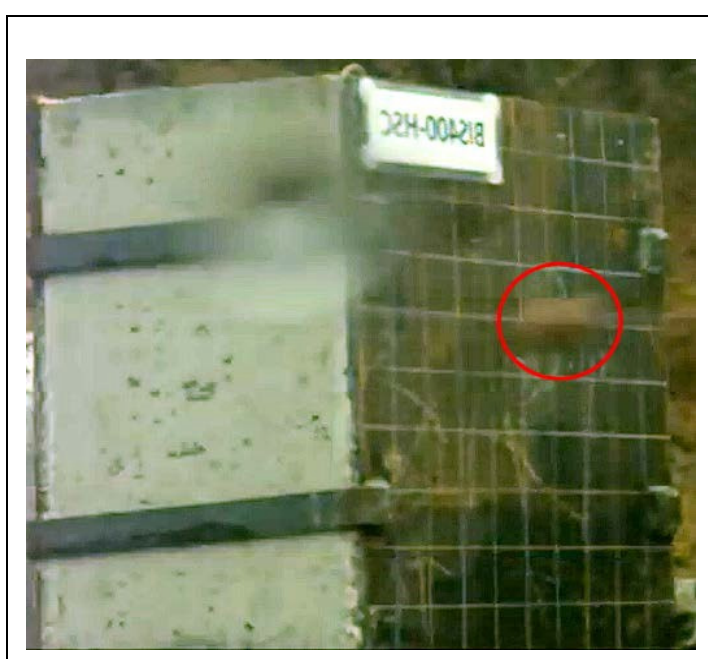

(a)

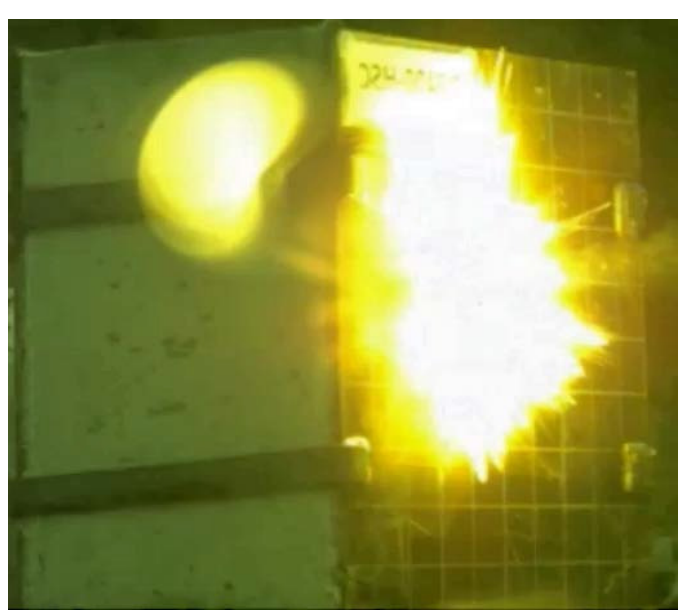

(b) 


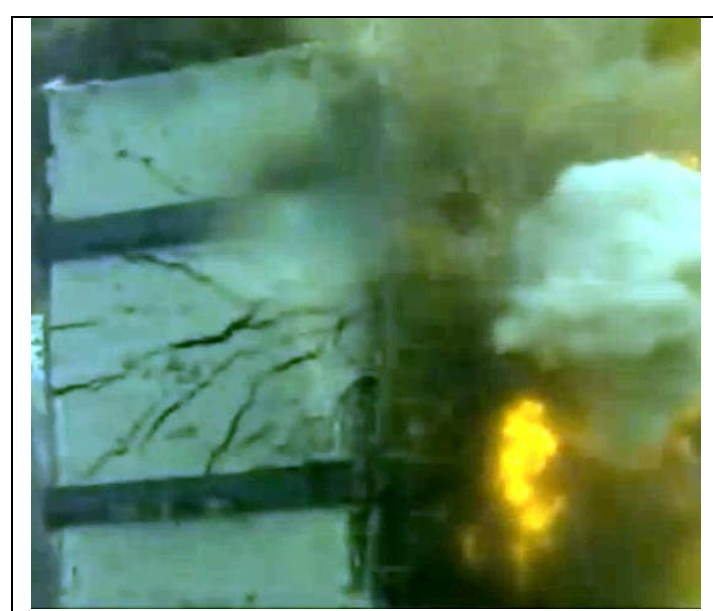

(c)

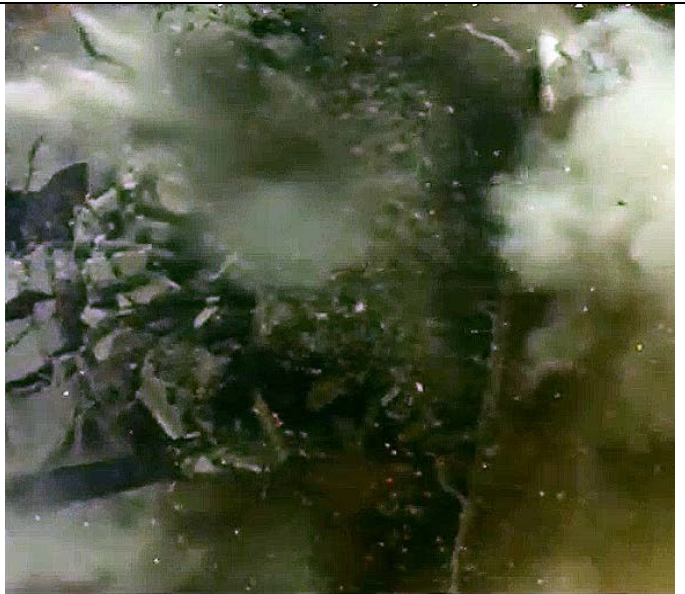

(d)

Figure 8: High-speed video frames showing the interaction between an EFP slug and the target at various stages: (a) EFP slug (red circle) prior to impact (time $=0 \mathrm{~ms}$ ); (b) Impact on the front steel plate (time $=\mathbf{0 . 6 0} \mathrm{ms}$ ); (c) initial cracking of the concrete core (time = $1.0 \mathrm{~ms})$; (d) target disintegration by EFP slug $($ time $=5.0 \mathrm{~ms})$

The typical global failure mode of the steel-concrete protective units of finite dimensions is demonstrated in Figure 8. All six "partially composite" protective units responded to the hypervelocity impact by the EFP in a similar fashion regardless of the steel plate grade and the concrete core strength. For all targets, the projectile impacted the block within $50 \mathrm{~mm}$ of the central point. The impact of the projectile resulted in the perforation of the front steel plate and the complete destruction of the concrete core for both normal strength and high strength concrete specimens. The concrete that formed the core of the protective unit scattered around the test site as shown in Figure 9.

One of the important findings of these tests was that the rear steel plate did not receive any damage for all six targets. This finding indicates that the front steel plate and the concrete core effectively absorbed the kinetic energy of the EFP, thereby protecting the rear steel plate from any damage. This finding has important consequences for the development of an effective protective system from EFPs based on sandwich construction, such as steel plates with a concrete core. 


\section{Figure 9: Typical failure mode of SC "partially-composite" sandwich blocks after} high-speed impact by EFP

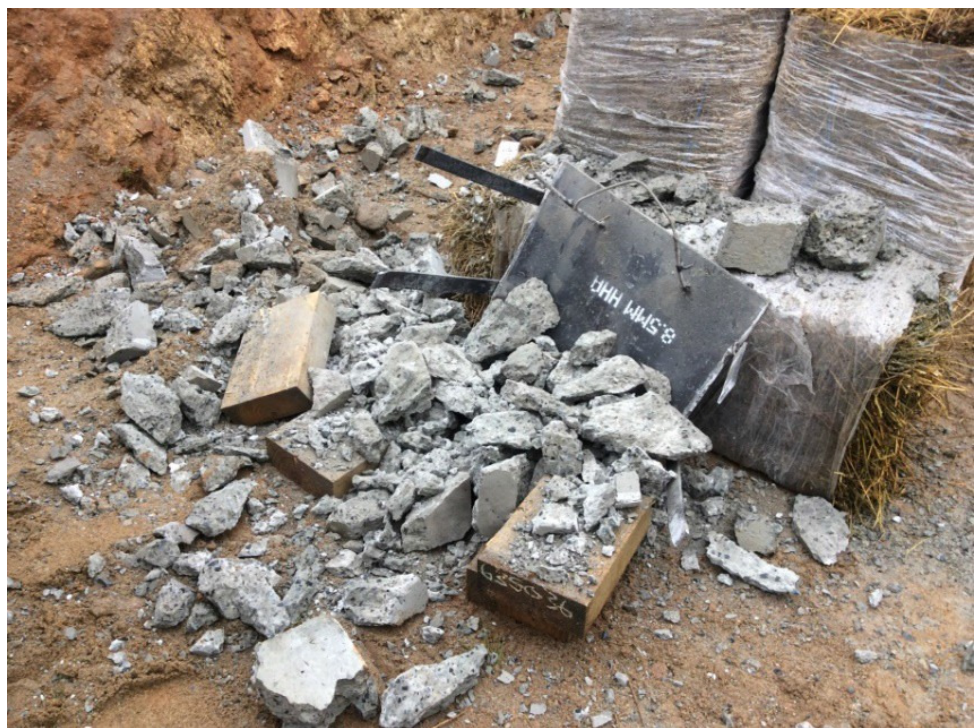

The front and rear steel plates of the steel-concrete sandwich targets performed differently in these tests. The steel plates that faced the EFP were perforated by the

299 projectiles forming slightly elongated holes with a maximum dimension of approximately

$300 \quad 60-65 \mathrm{~mm}$. The hole dimensions were similar for all three grades of high- strength steel

301 plates used for the targets. A typical front steel plate after impact is shown in Figure $30210(a)$.

303 Table 3 summarises the projectile penetration dimensions for the three types of high304 strength steel used for the front plates and two concrete grades. It can be observed that 305 the penetration dimensions are very similar for all three types of steel and not affected by 306 the concrete strength.

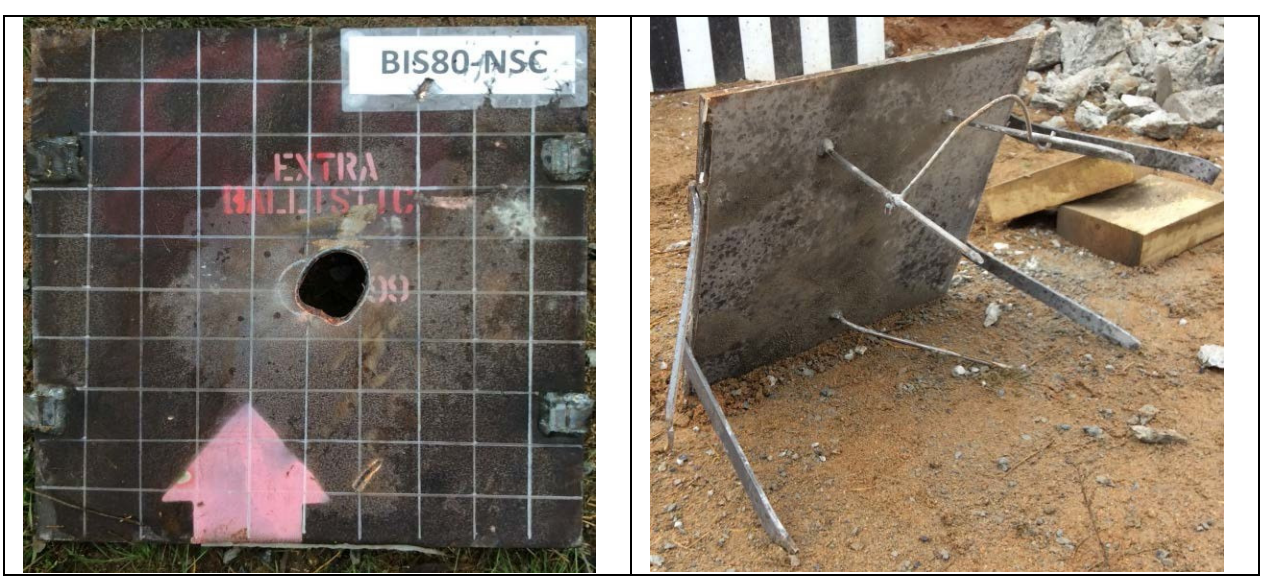


Figure 10: Steel face plates of the sandwich targets after impact by EFP: (a) perforation of the front steel plate; (b) intact rear face steel plate

310 Rear steel plates did not receive any damage after the EFP impact on the sandwich

311 target. The rear steel plate separated from the front plate due to fracture of the steel straps

312 and rod connectors welded between the two plates as shown in Figure 10(b). In all these

313 tests, the rear plates were not displaced from the testing location, which indicates that no

314 direct loading was transferred onto these plates by the impacting projectile. Based on

315 these experimental observations, it can be concluded that the tested designs of steel-

316 concrete sandwich blocks may be proposed as effective protective structures for

317 mitigating the highly destructive effects of EFPs on infrastructure and critical structural

318 components.

319 Table 3: Comparative performance of front steel plates of different steel grades

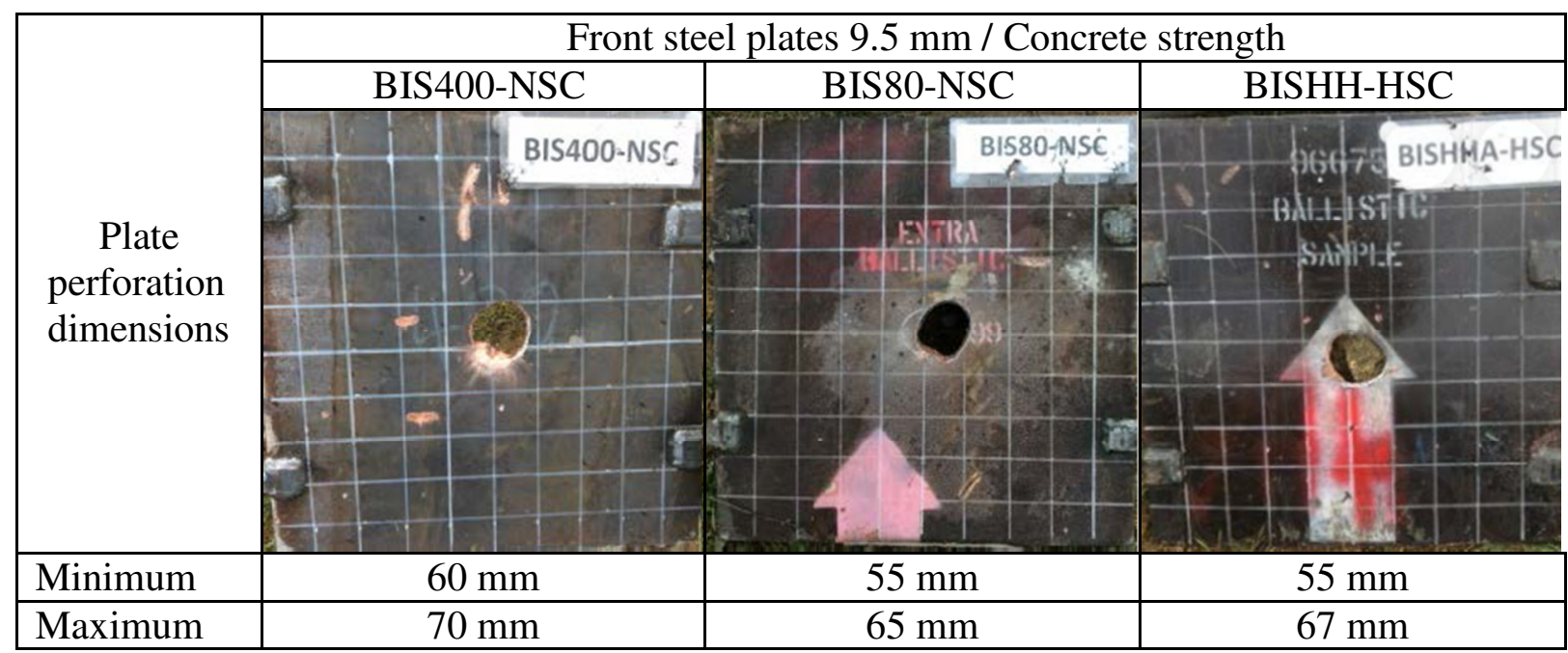

\subsection{Performance of SC Unit with Unreinforced Core and Fully Restrained Face}

Plates

323 To investigate the effect of fully restrained steel faceplates, the SC protective system was

324 developed with four high-strength bolts of $16 \mathrm{~mm}$ diameter as shown in Figure 11(a). The

325 concrete core had a thickness of $300 \mathrm{~mm}$ and a compressive strength of $42 \mathrm{MPa}$. The high- 
strength bolts were designed to prevent outward motion of the steel face plates by estimating momentum of the steel plates from the measured outward velocities and their masses.

Figure 11(b) depicts a target unit BIS500-NSC-BOLTS after being struck by an EFP flying with a velocity of $1200 \mathrm{~m} / \mathrm{s}$. The failure mode for the BIS500-NSC-BOLTS unit included perforation of the front steel plate and complete disintegration of the concrete core. The rear steel plate was intact thereby indicating that the EFP was arrested by the concrete core. The high-strength bolts effectively restrained the steel face plates against outward motion with only minor plastic deformation around the bolt holes.

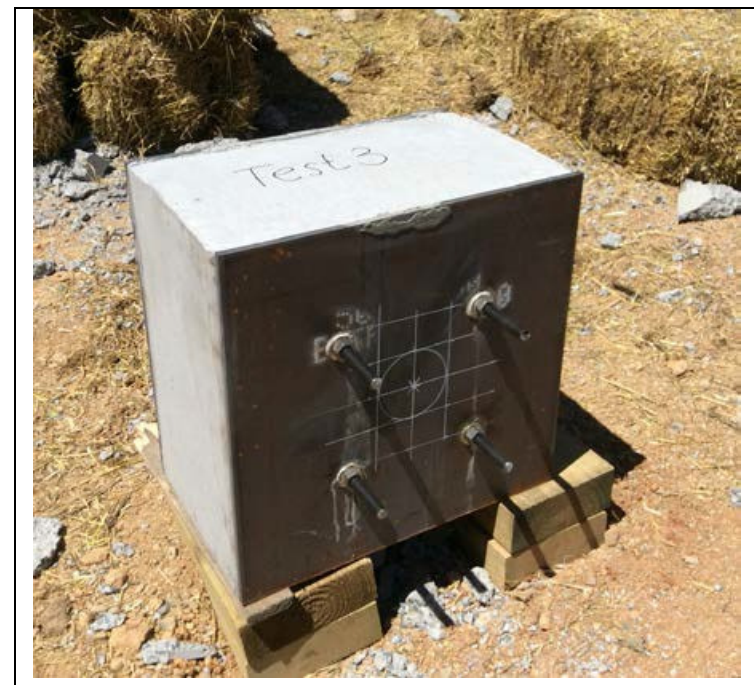

(a)

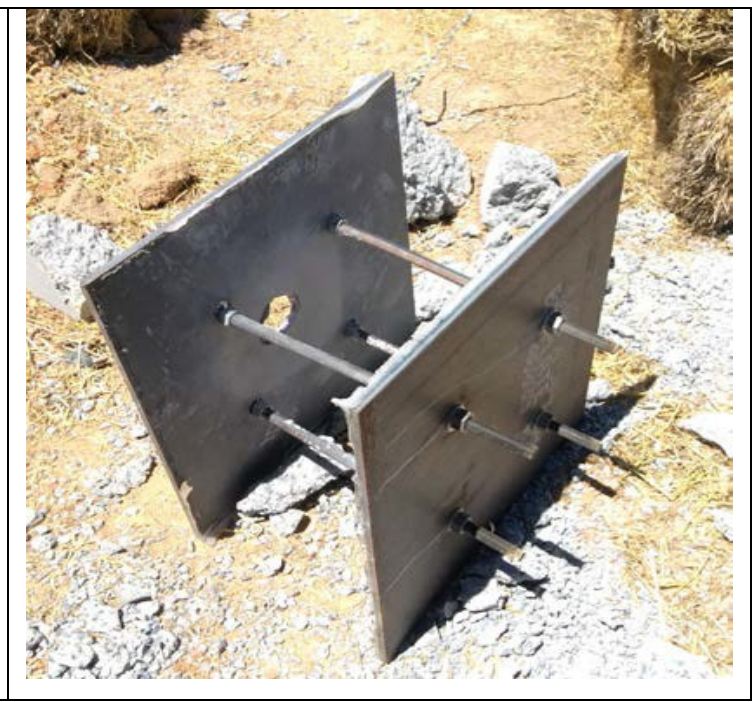

(b)

Figure 11: Target unit BIS500-NSC-BOLTS: (a) Before impact by EFP; (b) After impact by EFP

The performance of the target units with fully-restrained steel face plates demonstrated that these units can be effective as protective barriers for mitigating hypervelocity impacts by explosively formed projectiles.

\subsection{Performance of SC Unit with Reinforced Core and Unrestrained Face Plates}

Steel liners and jackets are widely used for retrofitting reinforced concrete structural elements against the effects of blast and impact. A target unit BIS500-NSC-REO (Figure 12(a)) was developed to investigate the effect of a steel mesh reinforced concrete core on the 
344 overall performance of the SC protective system subjected to hypervelocity impacts by 345 EFPs. The reinforced details included two welded steel meshes of $10 \mathrm{~mm}$ deformed bars 346 with a spacing of $100 \mathrm{~mm}$ in both directions. The concrete cover was $20 \mathrm{~mm}$ for both steel 347 meshes. The meshes were connected with shear links made from the same reinforcing bars 348 to form an effective confining cage for the concrete core.

349 As can be observed in Figure 12(b), the EFP penetrated the front steel plate 350 approximately $50 \mathrm{~mm}$ from the centre. The front steel plate separated from the concrete 351 core. The concrete core after the EFP impact is shown in Figure 12(c). Even though the 352 concrete core damage is quite extensive, one can notice the significantly improved overall 353 performance of the reinforced core compared to that of the SC blocks with an unreinforced 354 concrete core presented in Sections 4.1-4.2. It appears that lateral confinement afforded by 355 steel meshes and steel shear links is an effective mechanism for reducing fragmentation of 356 the concrete core following a hypervelocity impact by EFPs.

357 Figure 12(d) shows that the rear steel plate remained bonded to the concrete core and did 358 not experience any damage. This observation indicates that the reinforced concrete core of $359300 \mathrm{~mm}$ thickness effectively terminated the EFP and absorbed the shock impulse produced 360 by the EFP hypervelocity impact. These experimental results provided an important design 361 outcome; that the SC protective system with a reinforced concrete core is an effective means 362 of protection from hypervelocity EFP impacts with reduced fragmentation hazards from the 363 protective barrier. 


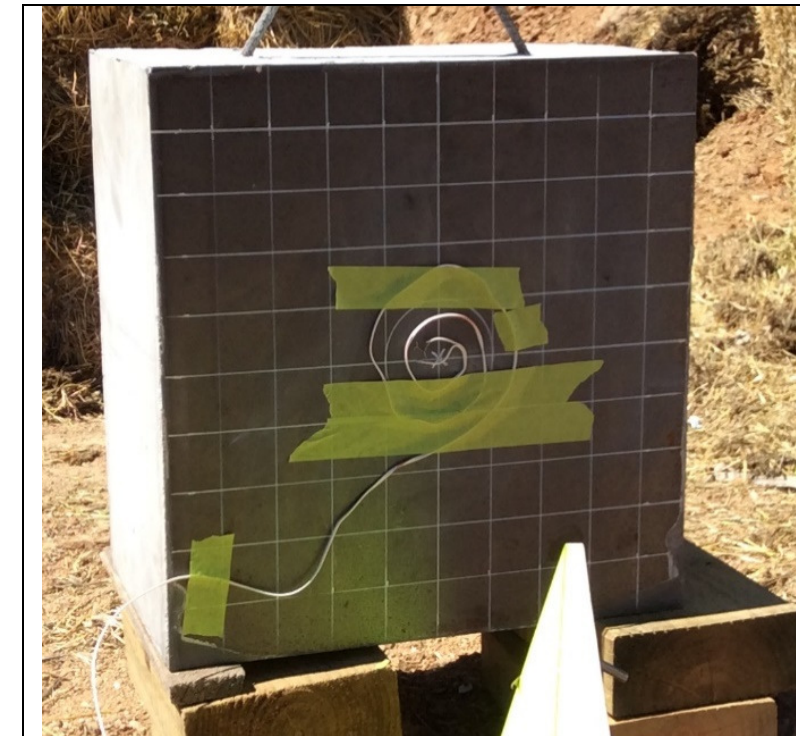

(a)

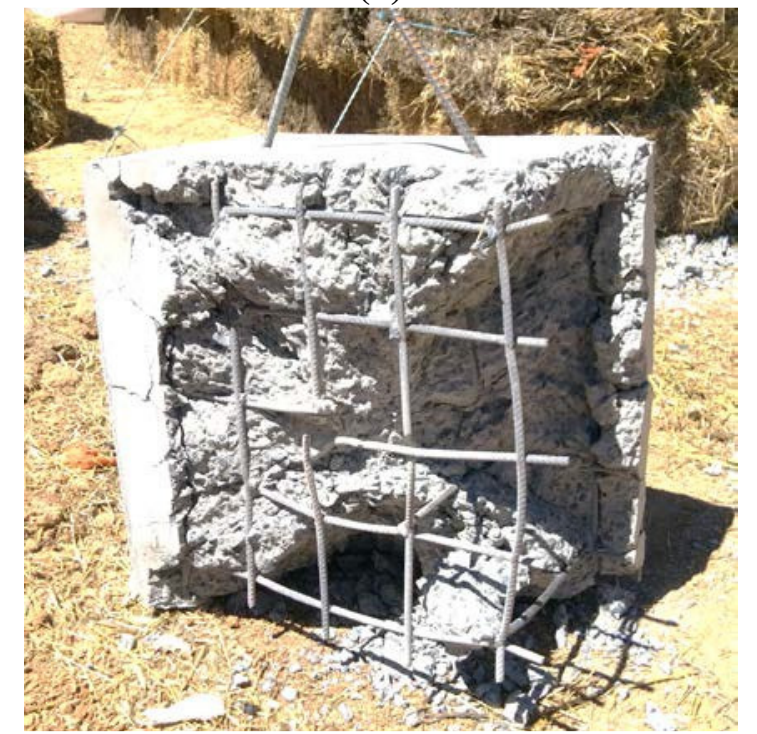

(c)

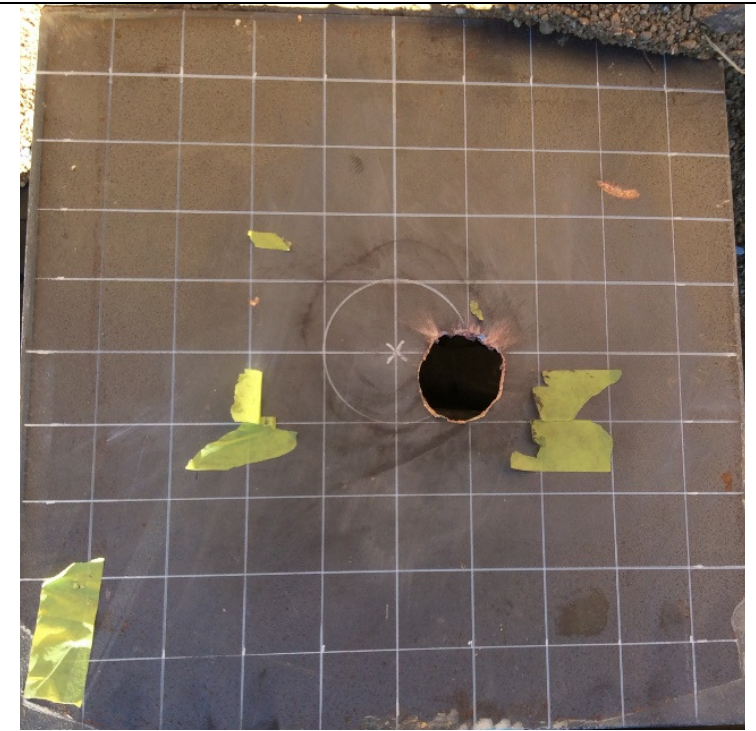

(b)

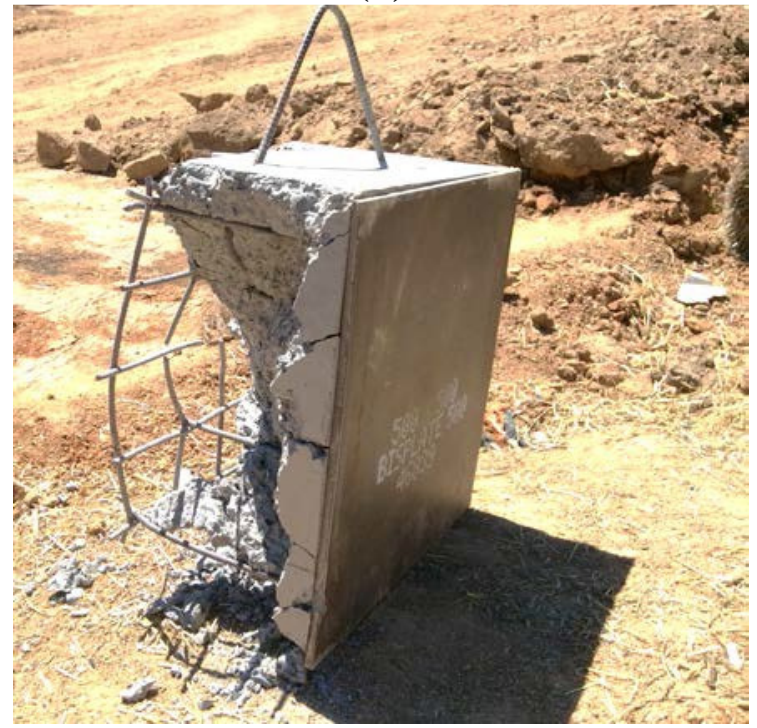

(d)
365

366

367

368

369

Figure 12: Target unit BIS500-NSC-REO after impact by EFP: (a) View of the block prior to testing; (b) Perforated front plate; (c) View from the impact side after EFP impact; (d) View from the rear side after EFP impact 


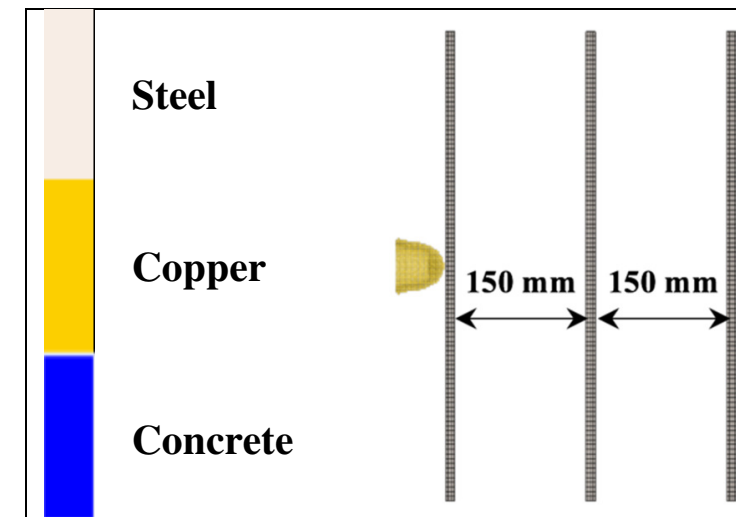

(a)

\subsection{Description of Computer Models}

\section{NUMERICAL SIMULATION OF THE INTERACTION OF EFP WITH STEEL-CONCRETE PROTECTIVE BARRIER UNITS}

In this study, computer simulations were performed using the ANSYS Autodyn 17.1 [14] software. Full 3D models were developed to study the ballistic performance of various configurations of barrier units (see Figure 13). The impact response of spaced steel plates was first investigated to establish the maximum perforation capacity of the slug formed from a $100 \mathrm{~mm}$ calibre EFP device. Next, the effect of a concrete core sandwiched in between two parallel steel plates is investigated. In an effort to optimise the design of the barrier unit, several variations were numerically investigated. The variations included modelling SC units with concrete cores with varying thicknesses (e.g. $150 \mathrm{~mm}, 100 \mathrm{~mm}$, and $100 \mathrm{~mm}$ ), and the removal of the front face plate. Recommendations for future designs of barrier units to protect against EFPs are then made based on the conclusions drawn from the entire study. plates; (b) penetration of steel-concrete target sandwich block

The EFP slug was modelled based on the exact geometry of the actual slug recovered from the field test for maximum accuracy (see Figure 14). This was achieved by digitising the actual projectile using a 3D-scanner and importing into Autodyn as a 3D surface mesh. The EFP slug as well as the concrete core was defined with the Smooth Particle Hydrodynamics 
would typically suffer from severe grid distortions and tangling. However, it is to be noted that the SPH method is computationally expensive and is less efficient than conventional methods and should therefore be employed sensibly [15].

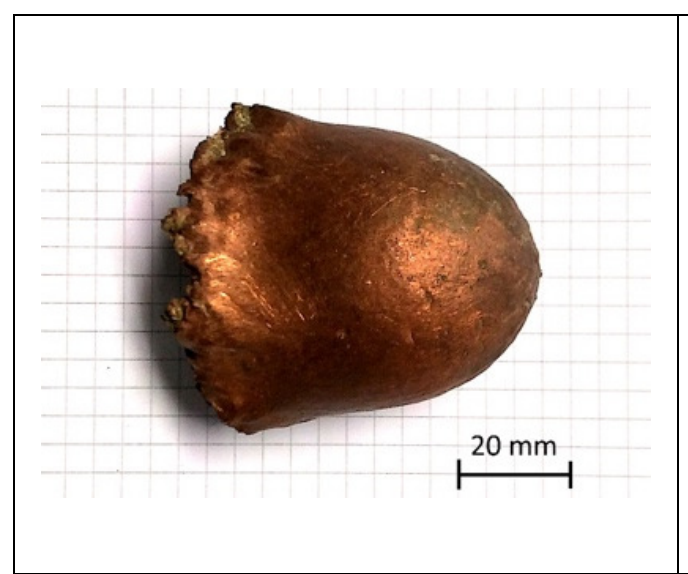

(a)

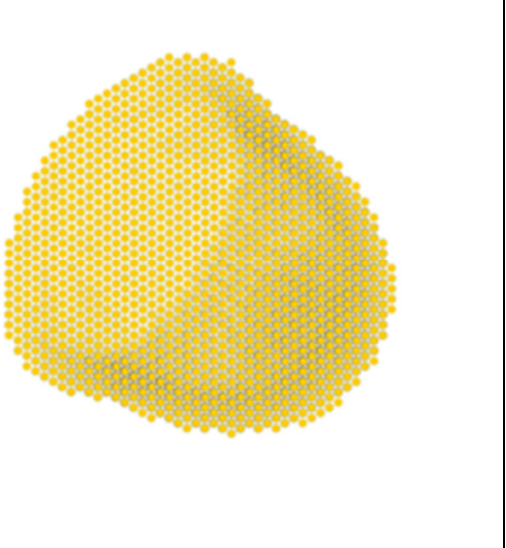

(b)

Figure 14: (a) Recovered EFP slug; (b) EFP slug discretised as SPH mesh for interacting with targets

The front face steel plate was discretised with the Arbitrary Lagrangian-Eulerian method (ALE) [14] to account for extremely high pressures and large deformations caused by hypervelocity impact. This method allows for the grid to be moved and remapped accordingly during the calculation process. This essentially minimises grid distortions and therefore reduces the occurrence of numerical instabilities normally experienced by "pure" Lagrangian grids while still allowing the overall calculation to be performed efficiently [15].

Interaction between all ALE and SPH parts was defined using the external gap contact algorithm [14]. A summary of the discretisation methods used to define the various parts in the computer models is given in Table 4.

Table 4: Summary of discretisation methods used in the numerical models

\begin{tabular}{|c|c|c|c|c|}
\hline \multirow[b]{2}{*}{ Part } & \multirow[b]{2}{*}{$\begin{array}{l}\text { Spaced steel } \\
\text { plates }\end{array}$} & \multicolumn{3}{|c|}{ Steel-concrete target sandwich blocks } \\
\hline & & $\begin{array}{c}50 \mathrm{~mm} \\
\text { concrete core }\end{array}$ & $\begin{array}{c}100 \mathrm{~mm} \\
\text { concrete core }\end{array}$ & $\begin{array}{c}150 \mathrm{~mm} \\
\text { concrete core }\end{array}$ \\
\hline EFP & $5639 \mathrm{SPH}$ nodes & \multicolumn{3}{|c|}{5639 SPH nodes } \\
\hline Concrete core & N/A & $\begin{array}{c}\text { 100k SPH } \\
\text { nodes }\end{array}$ & $\begin{array}{c}\text { 200k SPH } \\
\text { nodes }\end{array}$ & $\begin{array}{c}\text { 300k SPH } \\
\text { nodes }\end{array}$ \\
\hline Steel plates & $\begin{array}{l}\text { 150k hex ALE } \\
\text { elements }\end{array}$ & \multicolumn{3}{|c|}{ 100k hex ALE elements } \\
\hline
\end{tabular}




\subsection{Material Constitutive Modelling}

407 In the numerical models, the strength behaviours of the EFP slug and steel plates are 408 represented by the Johnson-Cook material model (refer to equation (2)) which describes

409 the strength behaviour of metals experiencing large strains, high strain rates, and high 410 temperatures which is suited for the high velocity impact of the present problem [14].

$411 \sigma_{y}=\left(A+B \varepsilon_{p}^{n}\right)\left(1+C \ln \dot{\varepsilon}^{*}\right)\left(1-T_{H}^{m}\right)$

412 where $\sigma_{y}$ is the yield stress while $A, B, C, n$, and $m$ are the material constants. $\varepsilon_{p}$ and $\dot{\varepsilon}^{*}$ 413 are the effective plastic and normalised effective plastic strain rate, respectively. $T_{H}=$

$414\left(T-T_{\text {room }}\right) /=\left(T_{\text {melt }}-T_{\text {room }}\right)$ represents the homologous temperature where $T_{\text {room }}$ and $415 T_{\text {melt }}$ are the room and melting temperatures, respectively.

416 The P-alpha equation of state model developed by Herrmann [16] was utilised to 417 represent the compaction behaviour of the concrete blocks, accounting for the relationship 418 of material compaction over a wide stress range while simultaneously giving reasonable 419 definition of compaction process for levels of low stress [14]. This is defined in equation $420 \quad(5):$

421

$\alpha=1+\left(\alpha_{i}-1\right)\left[\frac{p_{s}-p}{p_{s}-p_{e}}\right]^{n}$

422 where $\alpha$ is the material porosity, $p_{e}$ is initial compaction pressure at porous compaction, $423 \alpha_{i}$ is porous compaction while $p_{s}$ is solid compaction pressure, at full compaction 424 (i.e. $\alpha=1.0$ ), and $n$ is the compaction exponent.

RHT (Riedel-Hiermaier-Thoma) concrete strength model is used to describe the 426 dynamic loading of the concrete blocks [14]. This strength model combines the plasticity 
and shear damage model in which the material deviatoric stress is limited by a generalised

428 failure surface of the form of equation (6).

429

$f\left(P, \sigma_{e q}, \theta, \dot{\varepsilon}\right)=\sigma_{e q}-Y_{T X C(P)} * F_{C A P(P)} * R_{3(\theta)} *(F)_{R A T E(\dot{\varepsilon})}$

430 where $Y_{T X C}$ accounts for the fracture surface, $F_{C A P}$ accounts for reduction in deviatoric 431 strength under porous compression, $R_{3}$ is the third invariant dependence term which 432 represents the difference between compressive and tensile meridian, $(F)_{R A T E}$ is the strain 433 rate effect which is represented with increases in fracture strength with plastic strain rate.

434 Table 5 summarises the equation of states (EOS) and material models used to define all 435 the parts in the numerical models. While, Table 6 and Table 7 present the material 436 parameters of the parts imported from the Autodyn material library [14].

437

438 Table 5: Summary of EOS and material models

\begin{tabular}{lllll}
\hline \multicolumn{1}{c}{ Part } & \multicolumn{1}{c}{ Material } & \multicolumn{1}{c}{$\begin{array}{c}\text { Equation of } \\
\text { state }\end{array}$} & $\begin{array}{c}\text { Strength } \\
\text { model }\end{array}$ & Failure model \\
\hline EFP slug & Copper & Linear & Johnson-Cook & None \\
\hline Concrete block & $\begin{array}{l}\text { Normal } \\
\text { strength } \\
\text { concrete }\end{array}$ & P alpha & RHT concrete & RHT concrete \\
\hline Steel plates & $\begin{array}{l}\text { High hardness } \\
\text { high strength } \\
\text { steel }\end{array}$ & Linear & Johnson-Cook & None \\
\hline
\end{tabular}

439 
Table 6: Material parameters of EFP and steel plates

\begin{tabular}{lcc}
\hline \multicolumn{1}{c}{ Parameter } & EFP slug & Steel plates \\
\hline Material & Copper & Steel \\
\hline Density $\left[\mathrm{g} / \mathrm{cm}^{3}\right]$ & 8.960 & 7.830 \\
\hline Equation of state & Linear & Linear \\
\hline Bulk modulus $[\mathrm{kPa}]$ & $1.290 \mathrm{E} 8$ & $1.590 \mathrm{E} 8$ \\
\hline Specific heat $[\mathrm{J} / \mathrm{kgK}]$ & - & 477.000 \\
\hline Strength model & Johnson-Cook & Johnson-Cook \\
\hline Shear modulus $[\mathrm{kPa}]$ & $4.600 \mathrm{E} 7$ & $8.180 \mathrm{E} 7$ \\
\hline Yield stress $[\mathrm{kPa}]$ & $9.000 \mathrm{E} 4$ & $6.800 \mathrm{E} 5$ \\
\hline $\begin{array}{l}\text { Hardening constant } \\
{[\mathrm{kPa}]}\end{array}$ & $2.920 \mathrm{E} 5$ & $5.100 \mathrm{E} 5$ \\
\hline Hardening exponent & 0.310 & 0.260 \\
\hline Strain rate constant & 0.025 & 0.014 \\
\hline $\begin{array}{l}\text { Thermal softening } \\
\text { exponent }\end{array}$ & 1.090 & 1.030 \\
\hline Melting temperature $[\mathrm{K}]$ & 1356 & 1793 \\
\hline
\end{tabular}

Table 7: Material parameters of concrete blocks

\begin{tabular}{|c|c|c|c|c|c|}
\hline \multirow{2}{*}{ Parameter } & $\begin{array}{c}\text { Equation } \\
\text { of state }\end{array}$ & \multirow{2}{*}{ Parameter } & \multirow{2}{*}{$\begin{array}{c}\begin{array}{c}\text { Strength } \\
\text { model }\end{array} \\
\text { RHT } \\
\text { concrete }\end{array}$} & \multirow{2}{*}{ Parameter } & \multirow{2}{*}{$\begin{array}{c}\begin{array}{c}\text { Failure } \\
\text { model }\end{array} \\
\begin{array}{c}\text { RHT } \\
\text { concrete }\end{array}\end{array}$} \\
\hline & P-alpha & & & & \\
\hline Material & Concrete & $\begin{array}{l}\text { Shear modulus } \\
{[\mathrm{kPa}]}\end{array}$ & $1.670 \mathrm{E} 7$ & $\begin{array}{l}\text { Damage constant, } \\
\text { D1 }\end{array}$ & 0.040 \\
\hline Density $\left[\mathrm{g} / \mathrm{cm}^{3}\right]$ & 2.750 & $\begin{array}{l}\text { Compressive } \\
\text { strength }(\mathrm{fc})[\mathrm{kPa}]\end{array}$ & $3.500 \mathrm{E} 4$ & $\begin{array}{l}\text { Damage constant, } \\
\text { D2 }\end{array}$ & 1.000 \\
\hline $\begin{array}{l}\text { Porous density } \\
{\left[\mathrm{g} / \mathrm{cm}^{3}\right]}\end{array}$ & 2.314 & $\begin{array}{l}\text { Tensile strength } \\
(\mathrm{ft} / \mathrm{fc})\end{array}$ & 0.100 & $\begin{array}{l}\text { Minimum strain } \\
\text { to failure }\end{array}$ & 0.010 \\
\hline $\begin{array}{l}\text { Porous sound } \\
\text { speed }[\mathrm{m} / \mathrm{s}]\end{array}$ & 2920 & $\begin{array}{l}\text { Shear strength } \\
\text { (fs/fc) }\end{array}$ & 0.180 & $\begin{array}{l}\text { Residual shear } \\
\text { modulus fraction }\end{array}$ & 0.130 \\
\hline $\begin{array}{l}\text { Initial compaction } \\
\text { pressure }[\mathrm{kPa}]\end{array}$ & $2.330 \mathrm{E} 4$ & $\begin{array}{l}\text { Intact failure } \\
\text { surface constant A }\end{array}$ & 1.600 & & \\
\hline $\begin{array}{l}\text { Solid compaction } \\
\text { pressure }[\mathrm{kPa}]\end{array}$ & $6.000 \mathrm{E} 6$ & $\begin{array}{l}\text { Intact failure } \\
\text { surface exponent } \mathrm{N}\end{array}$ & 0.610 & & \\
\hline $\begin{array}{l}\text { Compaction } \\
\text { exponent }\end{array}$ & 3.000 & & & & \\
\hline $\begin{array}{l}\text { Bulk modulus } \\
{[\mathrm{kPa}]}\end{array}$ & $3.527 \mathrm{E} 7$ & & & & \\
\hline
\end{tabular}


446 In an effort to obtain quantitative as well as qualitative understanding of the penetration 447 performance of the EFPs for steel and concrete targets, the penetration of EFP into 448 multiple steel plate targets and steel-concrete sandwich blocks was studied numerically 449 using ANSYS Autodyn 17.1. Simulation results will be validated using experimental observations in Section 4 and high-speed video recordings of the experiments.

\subsubsection{Ballistic Performance of Spaced Steel Plates}

452 Impact response of spaced steel plates was investigated so as to establish the maximum 453 perforation capacity of the explosively formed projectile formed from a $100 \mathrm{~mm}$ calibre 454 EFP device. The $9.5 \mathrm{~mm}$ thick high-strength steel plates were spaced $150 \mathrm{~mm}$ apart as shown in Figure 13(a). The plates have dimensions of $500 \mathrm{~mm}$ x $500 \mathrm{~mm}$. The EFP slug was assigned an initial velocity of $1200 \mathrm{~m} / \mathrm{s}$ based on the results of motion analysis of the high-speed video recordings of the flying EFPs from the field explosive trials.

Figure 15 presents the simulation results for the interaction analysis of the EFPs and the spaced steel plates. The results indicate that the EFP flying with a velocity of 1200 $460 \mathrm{~m} / \mathrm{s}$ is likely to perforate two consecutively placed $9.5 \mathrm{~mm}$ thick steel plates and will be terminated by the third steel plate which will experience plastic bulging deformation but without perforation damage. As demonstrated by Figure 15(d), the penetration and

463 perforation process occur in about 1 millisecond leading to the termination of the 464 projectile. The results also show that the numerical model correctly captures the thermo465 hydrodynamics processes where the copper projectile explosively bonds with the steel 466 plug upon initial impact transient. This behaviour is confirmed experimentally and is 467 discussed in the subsequent sections. 


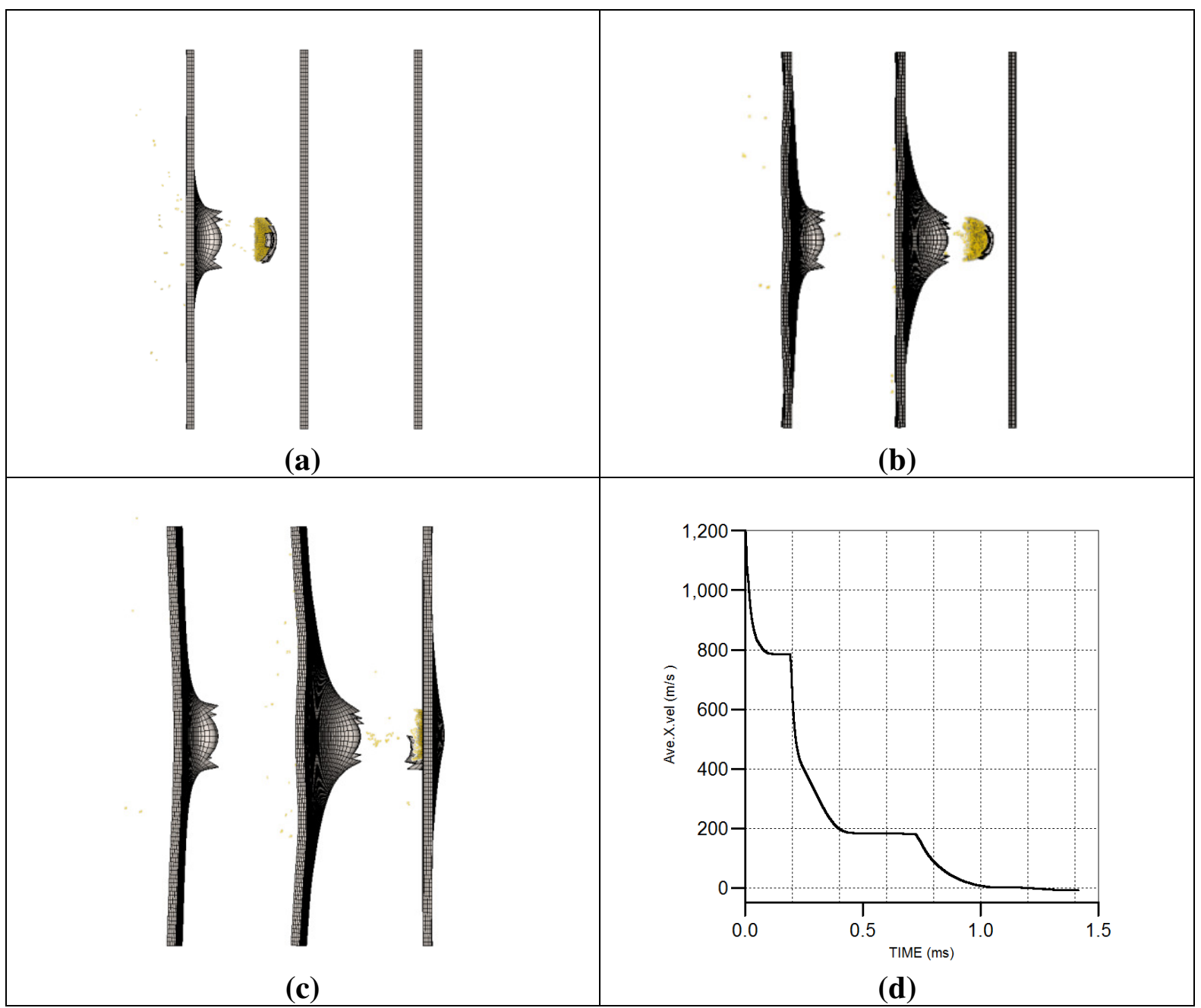

Figure 15: Interaction of the EFP with spaced steel plates: (a) perforation of first plate; (b) perforation of second plate; (c) deformation of third plate; (d) evolution of the EFP

\section{projectile velocity during the interaction with the three spaced steel plates}

\subsubsection{Ballistic Performance of $150 \mathrm{~mm}$ "Non-Composite” SC Blocks}

472 As evidenced by the results presented in Figure 15, an explosively formed projectile flying at a velocity of $1200 \mathrm{~m} / \mathrm{s}$ is likely to perforate two parallel $9.5 \mathrm{~mm}$ steel plates. Therefore, two steel plates with a concrete infill is investigated next so as to assess their performance when subjected to the hypervelocity impact by an EFP. The 3D model of the steel-concrete (SC) target unit with concrete infills of either $50 \mathrm{~mm}, 100 \mathrm{~mm}$, and $150 \mathrm{~mm}$ is shown in Figure

477 13(b). This model includes two high-strength steel plates modelled using ALE formulation and a concrete infill and copper EFP discretised with SPH. The target unit was modelled as non-composite panel with the steel plates and the concrete infill interacting only through the 

$\mathrm{m} / \mathrm{s}$ was taken from experimental motion analysis. experimentally recorded damage (Figure 16(a)) and numerically predicted damage contours (Figure 16(b)). The concrete core damage initiated at the impact location as well as through formation of cracks at the central horizontal and vertical planes of the block. At this time instant, the front and rear steel plates just started separating away from the concrete core which correlates well with the numerically predicted steel plate velocities in Figure 18(b).

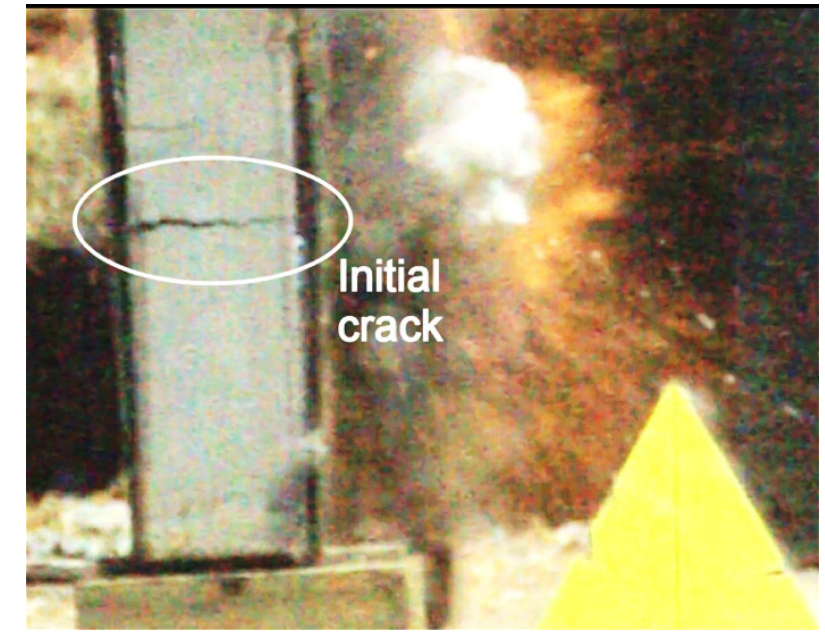

(a)

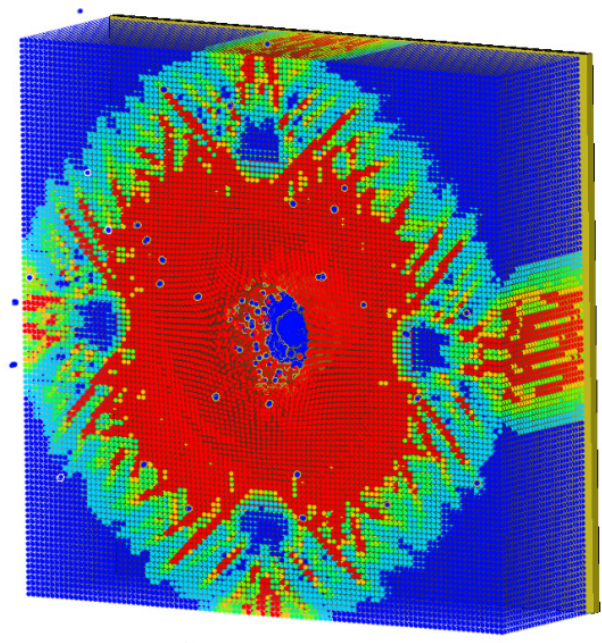

(b)

Figure 16: Concrete damage at $t=0.062 \mathrm{~ms}$ after impact: (a) initial horizontal crack from high-speed video recording; (b) predicted concrete damage by AUTODYN model at $0.062 \mathrm{~ms}$ (blue - intact material, red - fully fractured material)

Analysis of the numerical results provided information on the mechanics of EFP

494 penetration into a steel-concrete (SC) sandwich target. By plotting the time histories of 495 displacements and velocities for the projectile and steel plates, it is possible to better 496 understand the interaction between an EFP and the targets subjected to hypervelocity 497 impacts. 

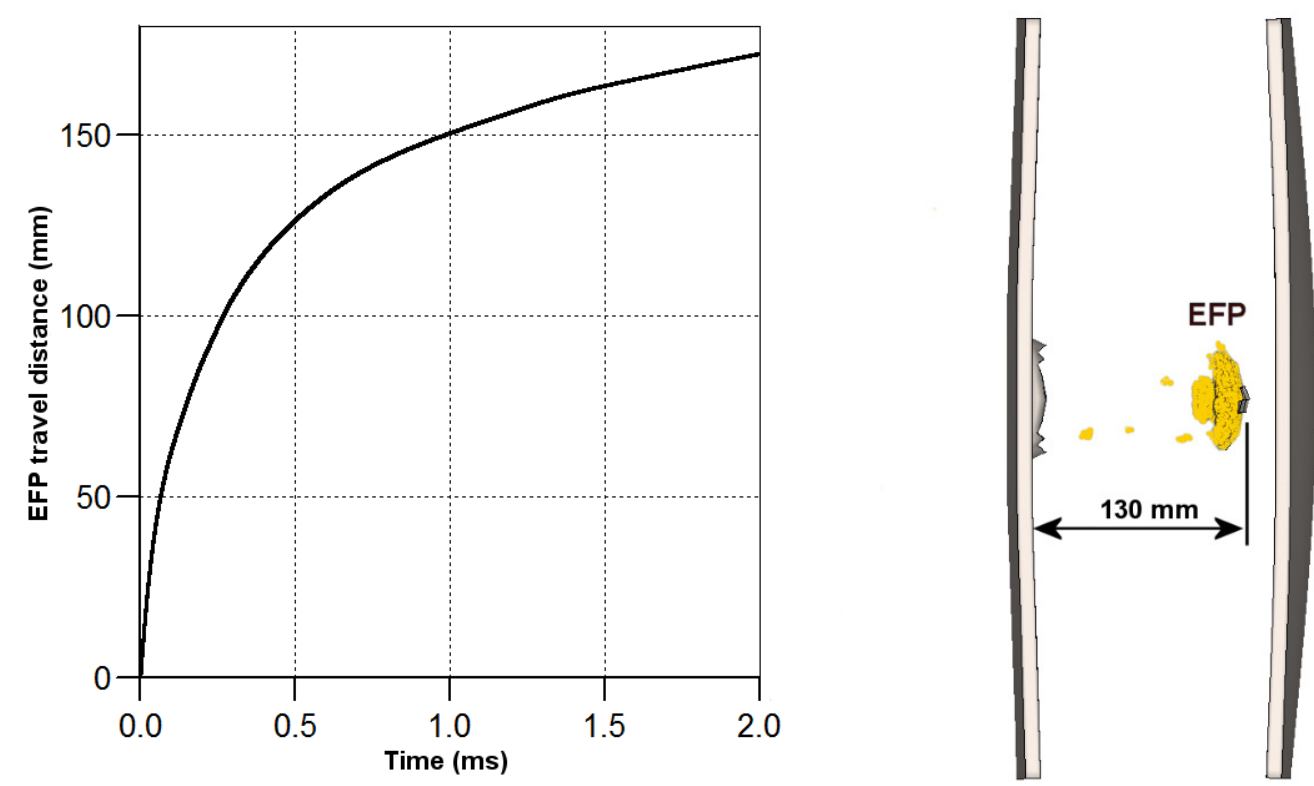

498

Figure 17: SC target panel response (with $150 \mathrm{~mm}$ concrete infill): (a) penetration depth of EFP travelling into concrete core; (b) EFP penetration in the SC "non-composite" panel (concrete infill is not shown) after $1 \mathrm{~ms}$

It can be observed from Figure 17(a), that it takes about $1.5 \mathrm{~ms}$ for the EFP to penetrate through the front face steel plate and full depth of the $150 \mathrm{~mm}$ concrete core. By this time, the projectile becomes moulded into a typical "mushroom" shape and is depicted in Figure 21. Analysis of the projectile and rear face plate velocities indicates that after $1.0 \mathrm{~ms}$ their velocities will attain approximately $35 \mathrm{~m} / \mathrm{s}$ (Figure 18(a)) and $17 \mathrm{~m} / \mathrm{s}$ (Figure 18(b)), respectively. The rear steel plate attains velocity due to the compressive wave induced by the impact impulse that travels through the concrete core and reflects from the steel-concrete interface. This finding explains why the rear steel plate was intact in the experiment - by the time the EFP had reached its resting position, the rear plate had already separated and flown away from the concrete core.

The graph in Figure 18(b) also confirms the observed behaviour of the front steel plate after getting struck by an EFP. After an initial impact transient which imposes very high pressure on the front steel plate in the impact zone, the front steel plate bounces back in the direction opposite to the impact. The acquired momentum is sufficiently high to fracture tension ties between front and rear steel face plates in "composite" designs of the sandwich 
517 blocks. These qualitative observations are also supported by the high-speed video recording

518 in Figure 16(a) and observations of the failure modes discussed in Section 4.
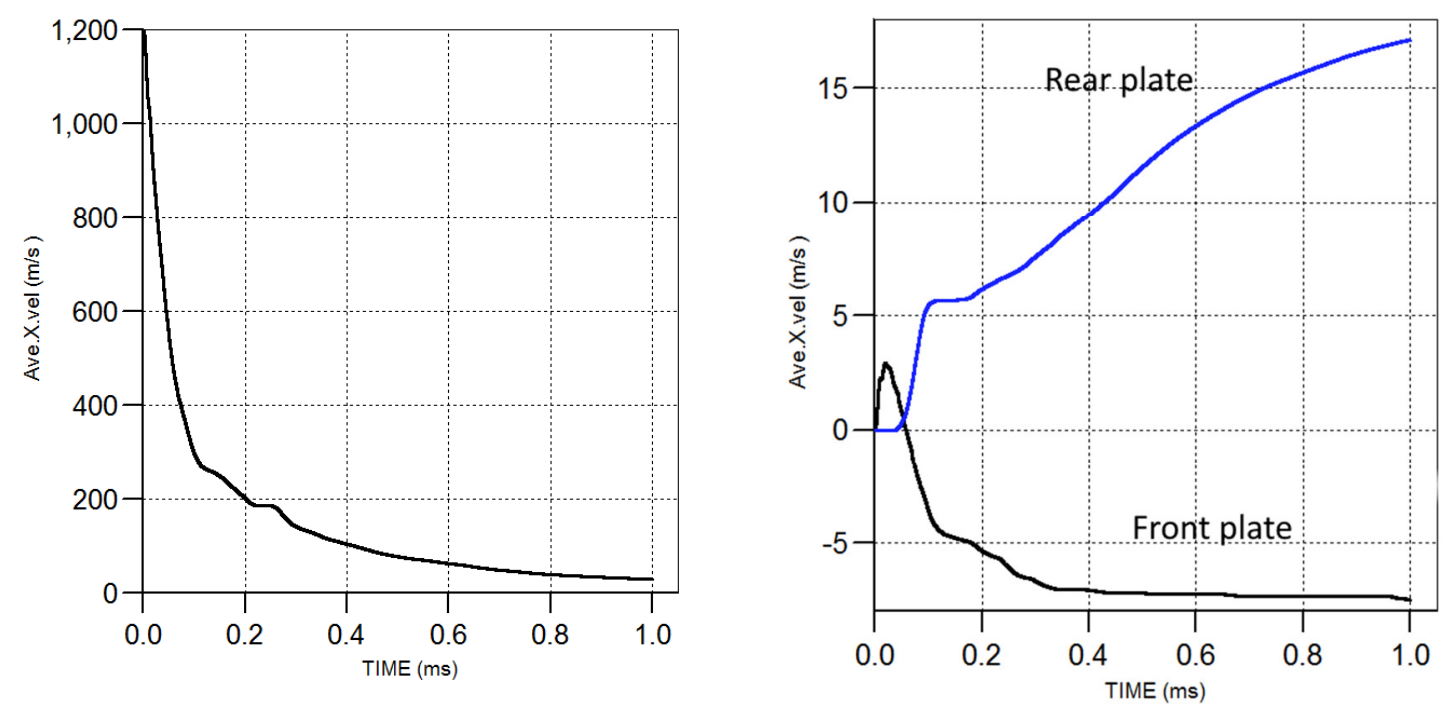

519

520

521

522

523

524

525

526

527

528

529
Figure 18: Interaction of the EFP with $150 \mathrm{~mm}$ SC target: (a) evolution of the EFP projectile velocity; (b) average velocities of front and rear steel plates in the noncomposite SC block

Behaviour of the concrete confined between the front and rear steel plates is characterised by rapid progression of damage originating from the point of impact, firstly across the concrete thickness, and then spreading towards the block edges. Figure 19 presents the evolution of contours for concrete damage after EFP impact. At $t=1.0 \mathrm{~ms}$, the EFP is practically terminated by the concrete. Similar to the experimental observations, the concrete core of the SC block is fully damaged and the projectile retains its "mushroom" shape in the process of concrete penetration. 

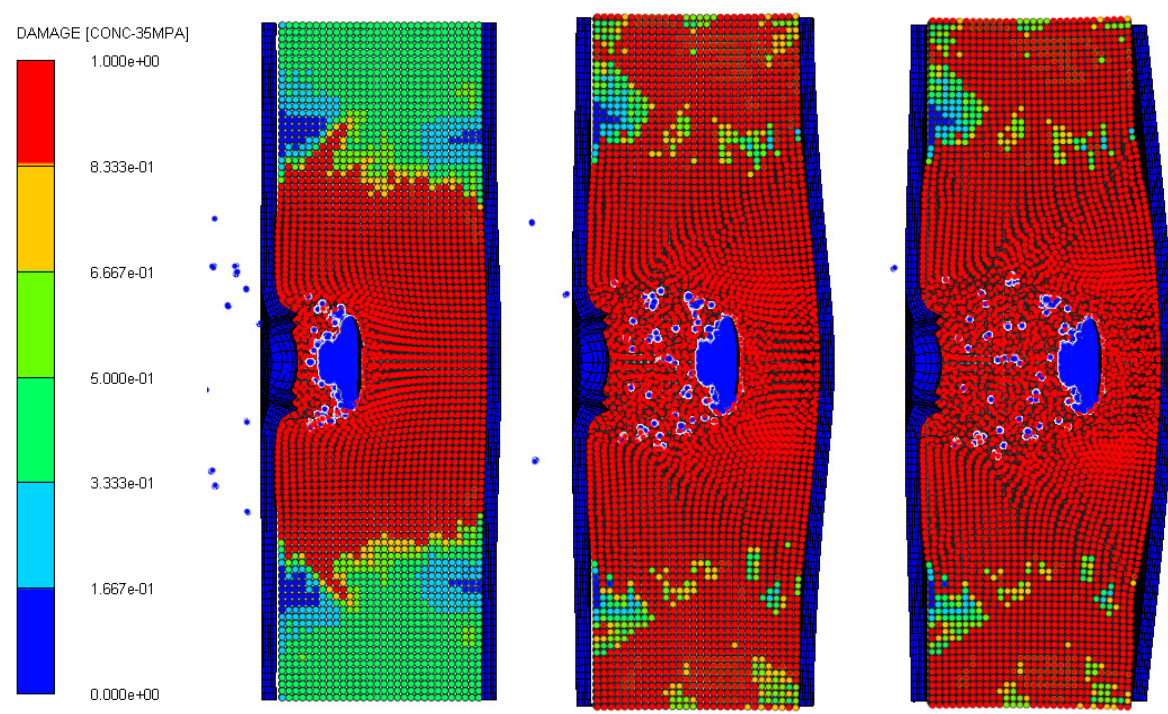

Figure 19: EFP penetration into $150 \mathrm{~mm}$ concrete core and evolution of concrete damage $(t=0.2 \mathrm{~ms}, 0.5 \mathrm{~ms}, 1.0 \mathrm{~ms})(0$ - intact material, 1 - fully fractured material $)$

Numerical simulations also allow for a better understanding of the localised concrete

534 behaviour in the vicinity of the EFP which is otherwise not possible with experimental measurement techniques. A material compression variable COMPRESS in Autodyn provides information on the changes in material density resulting from localised compressive pressures exerted by the EFP slug. The material compression variable COMPRESS is calculated as the natural logarithm function of the ratio of the current material density to the original density $\ln \left(\rho / \rho_{0}\right)$. Thus, COMPRESS $=0$ represents the original material density and COMPRESS $=-$

$540 \quad 0.5$ represents the reduction (i.e. softening) of about $40 \%$ from its original value. Figure 20

541 illustrates the progression of changes in the concrete density as the projectile penetrates into

542 the concrete core. It can be observed that as the EFP travels through the concrete core, it 543 leaves behind a cylindrical volume of crushed and pulverised concrete with a density of about $54460-75 \%$ of the original concrete density. On the other hand, the concrete in front of the 545 projectile is densified by $5-10 \%$ of the original density and continues providing its 546 contribution towards terminating the EFP. 

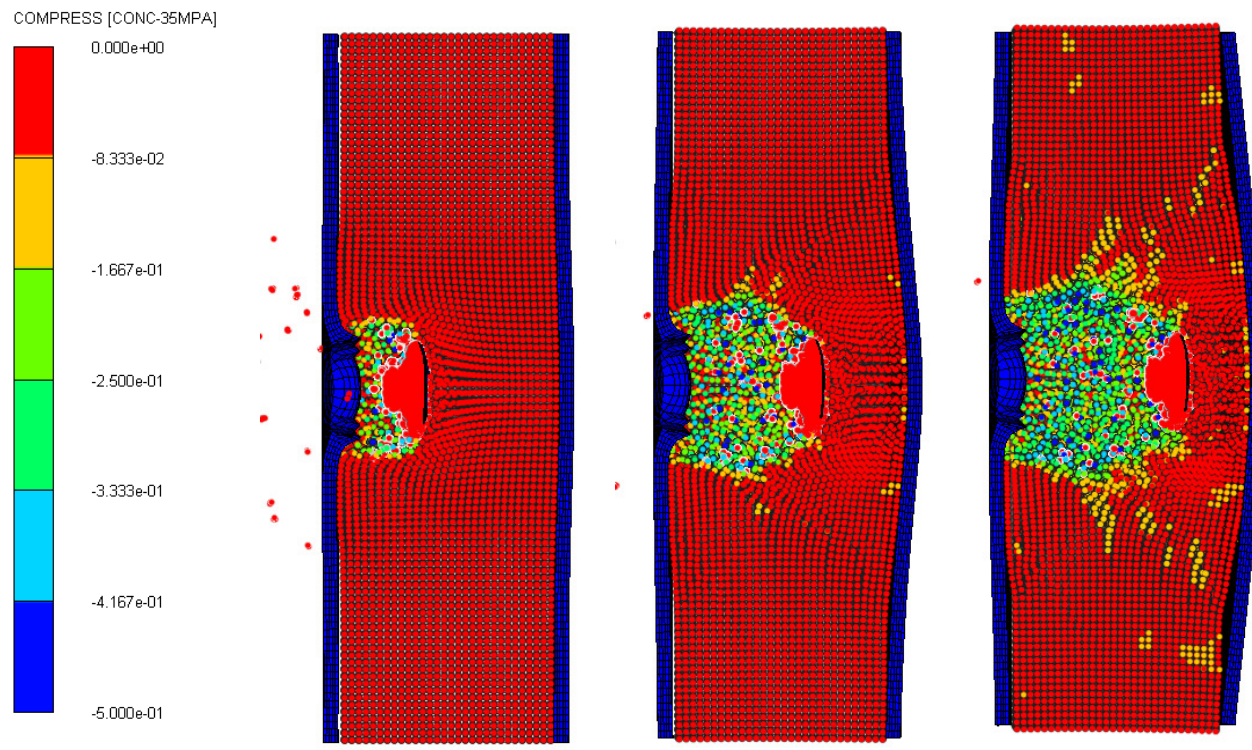

Figure 20: EFP penetration into $150 \mathrm{~mm}$ concrete core and changes in concrete material compression variable $C O M P R E S S=\ln \left(\rho / \rho_{0}\right)(t=0.2 \mathrm{~ms}, 0.5 \mathrm{~ms}, 1.0 \mathrm{~ms})$

550 Figure 21 validates the final shape of the explosively formed projectile after penetrating

551 through the steel-concrete target. The SPH model of the EFP slug (Figure 21(a)) simulated

552 the final deformed shape quite realistically - capturing all important features and overall

553 dimensions of the EFP slug recovered after the tests (Figure 21(b)). The model reproduced

554 the typical "mushroom" form of the projectile, the final mass, and the steel fragment bonded

555 to the copper projectile during the initial stage of hypervelocity impact on the front steel face 556 plate. 


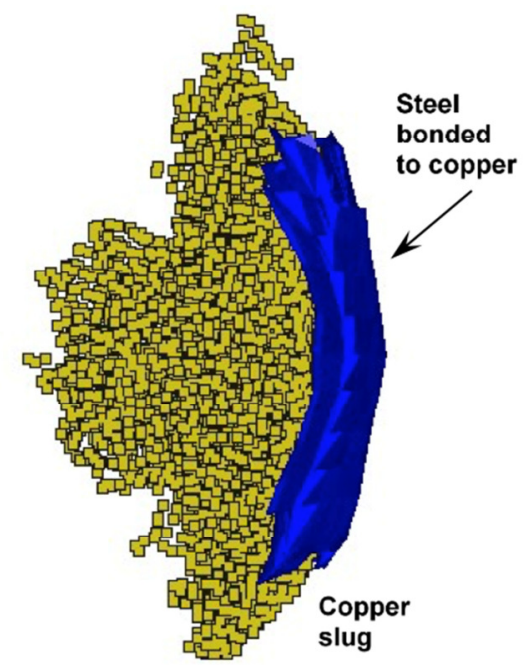

(a)

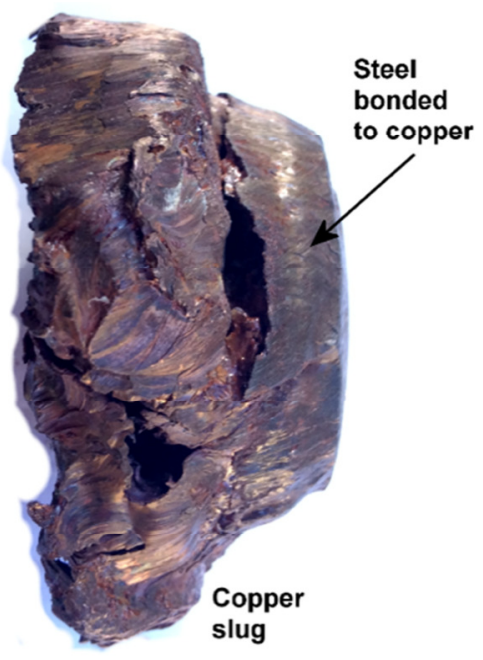

(b)

Figure 21: (a) Final shape of SPH model of the EFP after penetration into concrete; (b) recovered copper slug with steel plug bonded to the copper slug. Mass of the recovered slug is $425 \mathrm{~g}$

\subsubsection{Ballistic Performance of $100 \mathrm{~mm}$ "Non-Composite” SC Blocks}

Following the findings of the previous section where an explosively formed projectile flying at a velocity of $1200 \mathrm{~m} / \mathrm{s}$ is successfully terminated by a $150 \mathrm{~mm}$ thick concrete core sandwiched in between two steel plates, a parametric study is performed to investigate the ballistic performance of SC blocks when the thickness of the concrete core is varied (i.e. 100 $\mathrm{mm}$ and $50 \mathrm{~mm}$ ) as well as when the front face steel plate is absent.

Figure 22 illustrates the process of the EFP interaction with an SC block with a $100 \mathrm{~mm}$ thick concrete core. At the initial stages of the front face steel plate perforation and initial penetration into the concrete core, the ballistic performance of SC block is similar to that of the SC block with a $150 \mathrm{~mm}$ thick concrete core. Major differences in the ballistic performance however, can be observed after about $0.6 \mathrm{~ms}$ from the initial impact, when the EFP comes into contact with the rear face steel plate. For an SC block with a $100 \mathrm{~mm}$ concrete core, it appears that the terminal ballistic performance is controlled by the presence of the rear face steel plate. The velocity of the EFP after penetrating through the concrete core is relatively low and is not sufficient for perforating the rear face steel plate. However, 
577 for the EFPs with higher initial impact velocities than $1200 \mathrm{~m} / \mathrm{s}$, a thicker rear face steel plate 578 would need to be selected to avoid possible perforation damage.

579

580

581

582

583

584

585

586
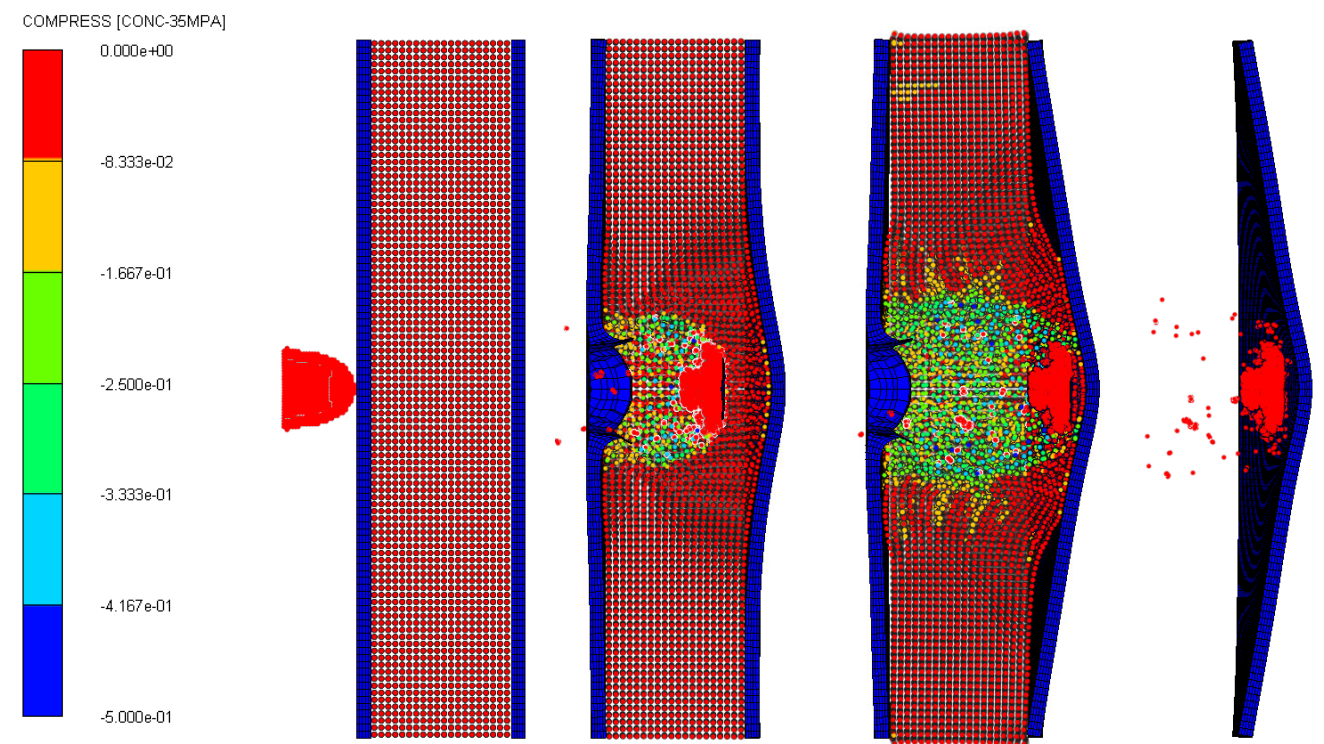

Figure 22: EFP penetration into $100 \mathrm{~mm}$ concrete core and changes in concrete material compression variable COMPRESS $=\ln \left(\rho / \rho_{0}\right)(t=0.0 \mathrm{~ms}, 0.3 \mathrm{~ms}, 0.6 \mathrm{~ms}, 0.8 \mathrm{~ms})$

As can be seen from Figure 23(a), the EFP velocity curve becomes nearly flat at $t=0.8 \mathrm{~ms}$ as both the EFP and the rear steel plate have acquired the same outward velocities. Analysis of the velocities of the front and rear steel plates shown in Figure 23(b) indicates that the plates acquired outward velocities of about $7 \mathrm{~m} / \mathrm{s}$ and $27 \mathrm{~m} / \mathrm{s}$, respectively within $0.8 \mathrm{~ms}$ after impact. 

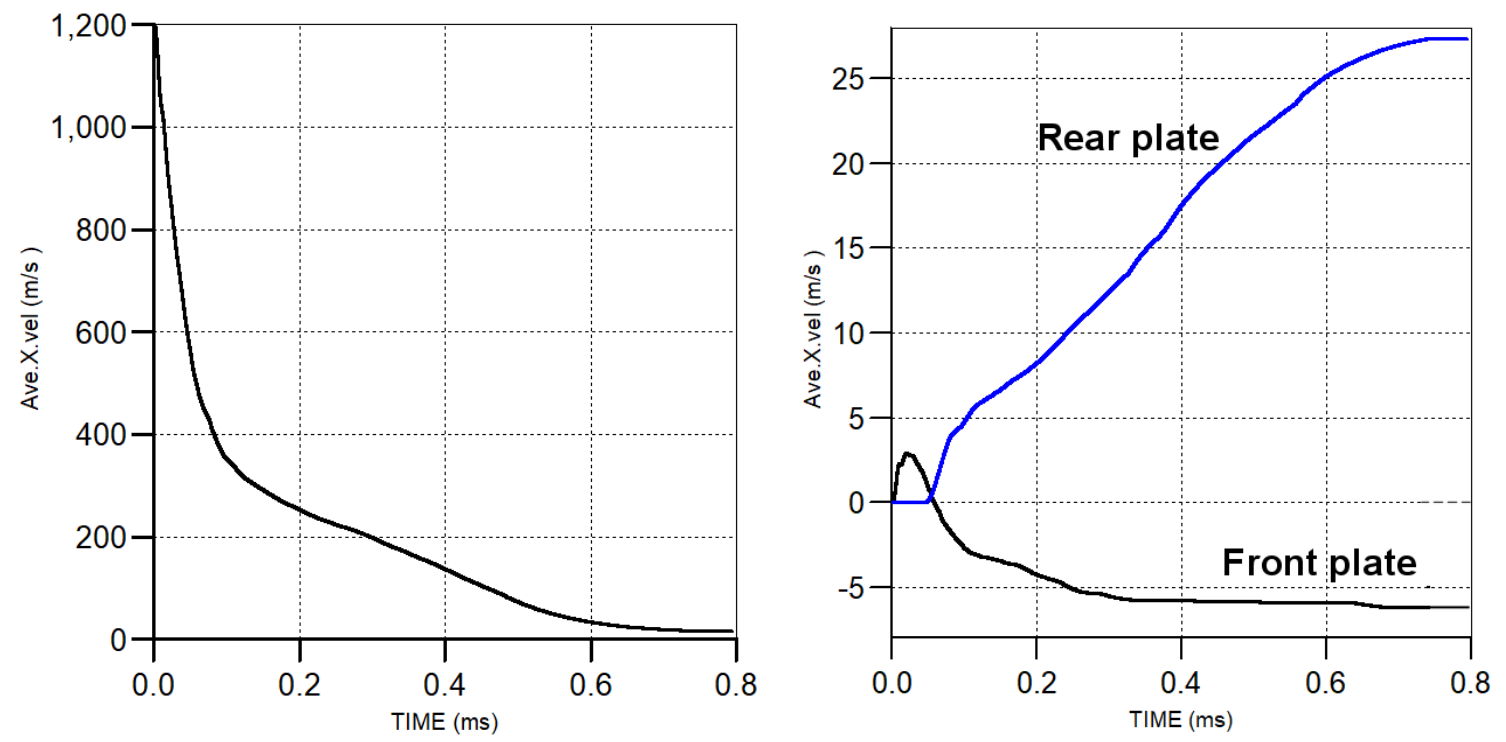
projectile velocity; (b) average velocities of front and rear steel plates in the noncomposite SC block

\subsubsection{Ballistic Performance of $50 \mathrm{~mm}$ "Non-Composite” SC Blocks}

592

In order to evaluate minimum required thickness for the concrete core to fully terminate an

EFP impacting an SC block at a velocity of $1200 \mathrm{~m} / \mathrm{s}$, a model of an SC block with a $50 \mathrm{~mm}$

594 thick concrete core was employed. Figure 24 presents the stages of EFP penetration into the

SC block with a $50 \mathrm{~mm}$ thick concrete core. Due to the relatively thin layer of concrete, the concrete in front of the EFP becomes crushed and its density is reduced even prior to the full penetration of the front face steel plate by the EFP. The compressive pressure exerted by the EFP on the concrete is transferred to the rear face steel plate causing its bulging. At $t=0.37 \mathrm{~s}$, the EFP comes into contact with the rear face steel plate - by this time its velocity is relatively low and therefore not sufficient to perforate the rear face steel plate. 

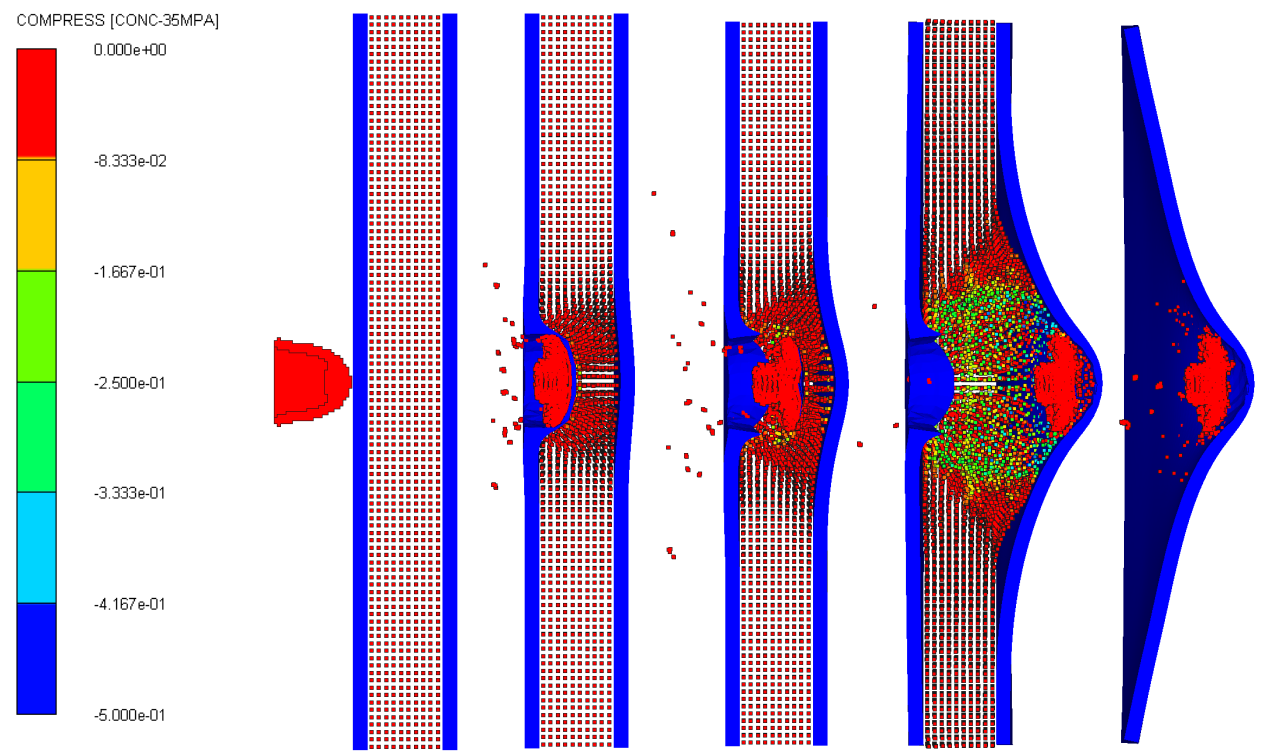

Figure 24: EFP penetration into $50 \mathrm{~mm}$ concrete core and changes in concrete material compression variable $C O M P R E S S=\ln \left(\rho / \rho_{0}\right)(t=0.0 \mathrm{~ms}, 0.06 \mathrm{~ms}, 0.10 \mathrm{~ms}, 0.37 \mathrm{~ms}, 0.72$ ms)

Figure 25(a) shows the evolution of the projectile velocity during its penetration into an

SC block with a $50 \mathrm{~mm}$ thick concrete core. Interestingly, it can be observed that the EFP

velocity becomes terminated much faster and at a higher rate compared to the SC blocks with thicker concrete cores (Figure 18 and Figure 23). The faster termination of EFP could be attributed to the faster "activation" of the rear face plate due to the thinner concrete core.

610 Even before complete perforation of the front face steel plate by the EFP, the rear face plate

611 has already become deformed and already started contributing to the termination of the EFP.

While the rear face steel plate experiences large plastic localised bulging without rupture

613 for an EFP with an initial impact velocity of $1200 \mathrm{~m} / \mathrm{s}$ for this SC block configuration, a

614 faster EFP (e.g. $1800 \mathrm{~m} / \mathrm{s}$ or higher) could cause the rear face steel plate to be perforated.

Analysis of the velocities of the front and rear face steel plates presented in Figure 25(b)

616 indicates that the plates would move away from the concrete core at velocities of about $6 \mathrm{~m} / \mathrm{s}$

617 and $34 \mathrm{~m} / \mathrm{s}$, respectively within approximately $1.0 \mathrm{~ms}$ after impact.

618 Overall, a $50 \mathrm{~mm}$ concrete core may be recommended as the minimum thickness for the

619 SC protective barriers. Since the thickness of the rear steel plate becomes a controlling design 

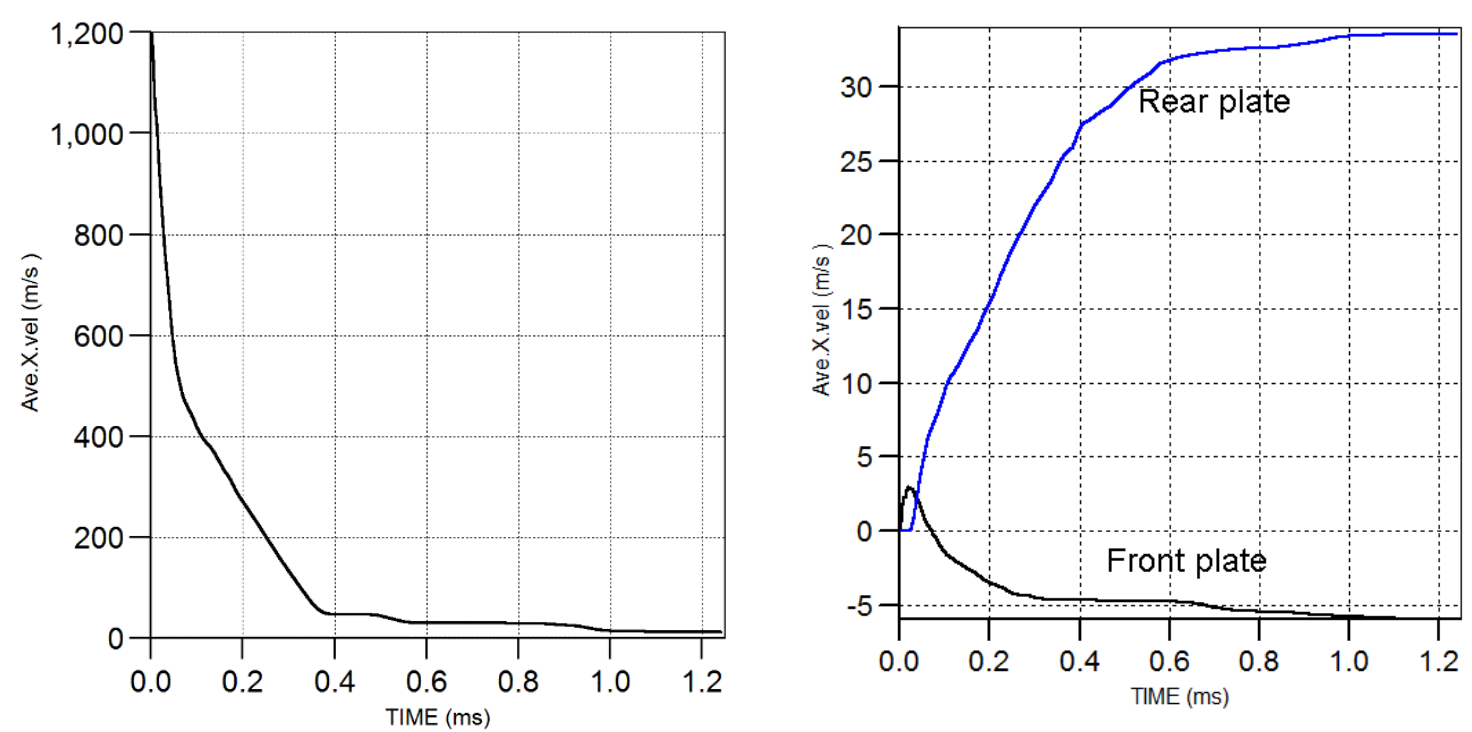

623

624

625

626

627

628

629

630

631

632

633

634

635

636

637
Figure 25: (a) evolution of the projectile velocity during penetration of $50 \mathrm{~mm}$ SC block; (b) average velocities of front and rear face steel plates in non-composite SC block 

ms after direct EFP impact. It can be observed that the EFP impact causes violent outburst of concrete fragments $(t=0.8 \mathrm{~ms})$ in the direction opposite to the impact. Furthermore, the concrete resistance causes erosion of the EFP which can be clearly seen at $t=0.15 \mathrm{~ms}$. This

642 phenomenon was not observed in the SC barrier designs with the front face steel plate. The

643 EFP erosion can be explained by observing the progression of concrete damage for the SC 644 blocks with and without front face steel plate (e.g. Figure 19 and Figure 26).

645 In Figure 19, one can notice that the concrete becomes fully fractured when an EFP is 646 penetrating through the front face steel plate. In this case, the EFP would travel through 647 concrete core that has already experienced strain-softening behaviour and would therefore 648 have less shear strength to contribute to the resistance of the EFP. Contrary to this behaviour, 649 when the front face is absent from the design (see Figure 26), the EFP would travel through 650 concrete which is only minimally damaged from the initial impact $(t=0.06 \mathrm{~ms})$ and would 651 therefore possess more resistance against the EFP. Significant EFP material erosion can be 652 observed to have occurred by the time the EFP penetrates through the entire thickness of the 653 concrete core $(t=0.15 \mathrm{~ms})$.
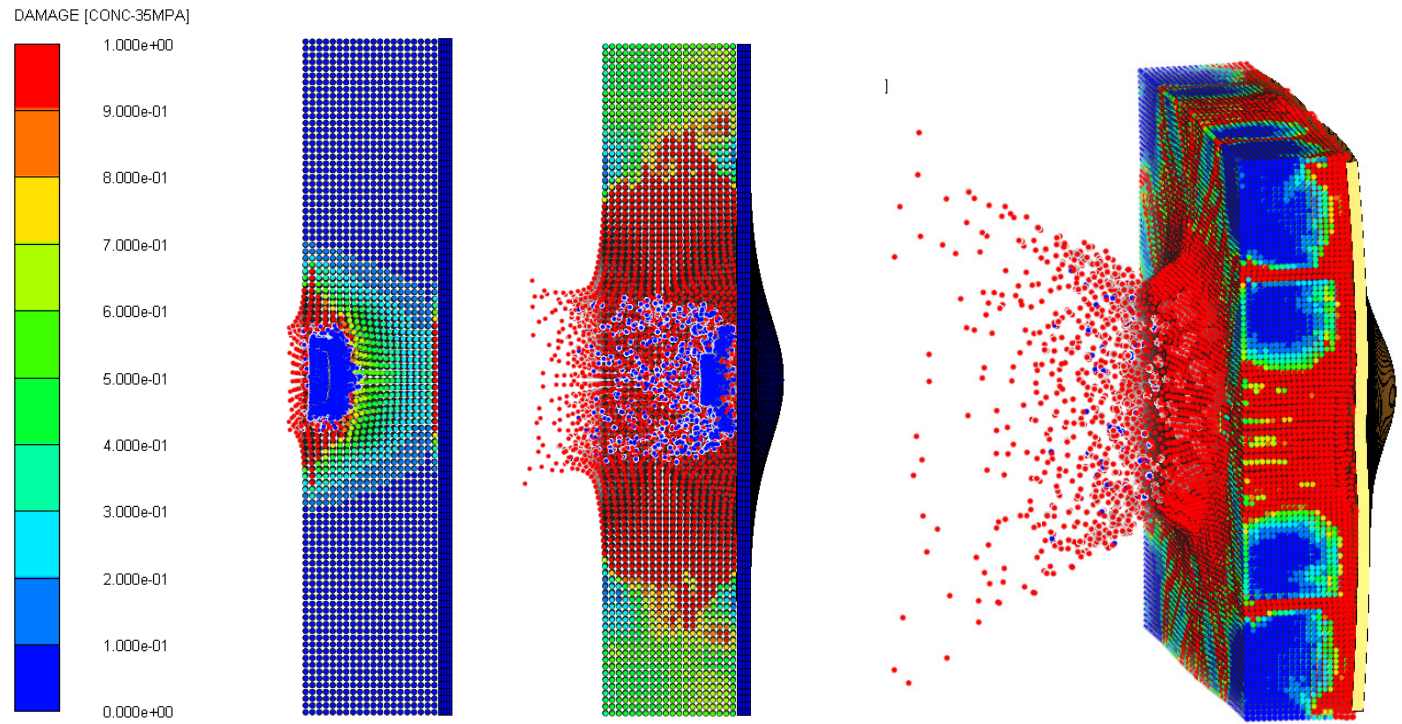

the above observed phenomena. As depicted in Figure 27, from the initial stages of EFP

659 penetration into the concrete core, a cloud of loose concrete fragments is formed that fly 660 outward with high velocity. At $t=0.08 \mathrm{~ms}$, the EFP is broken up into multiple copper 661 fragments, and concrete behind the EFP forms into a cloud of flying fragments which are 662 partially contained by the rear face steel plate.

663

664

665

666

667

668

669

670

671

672
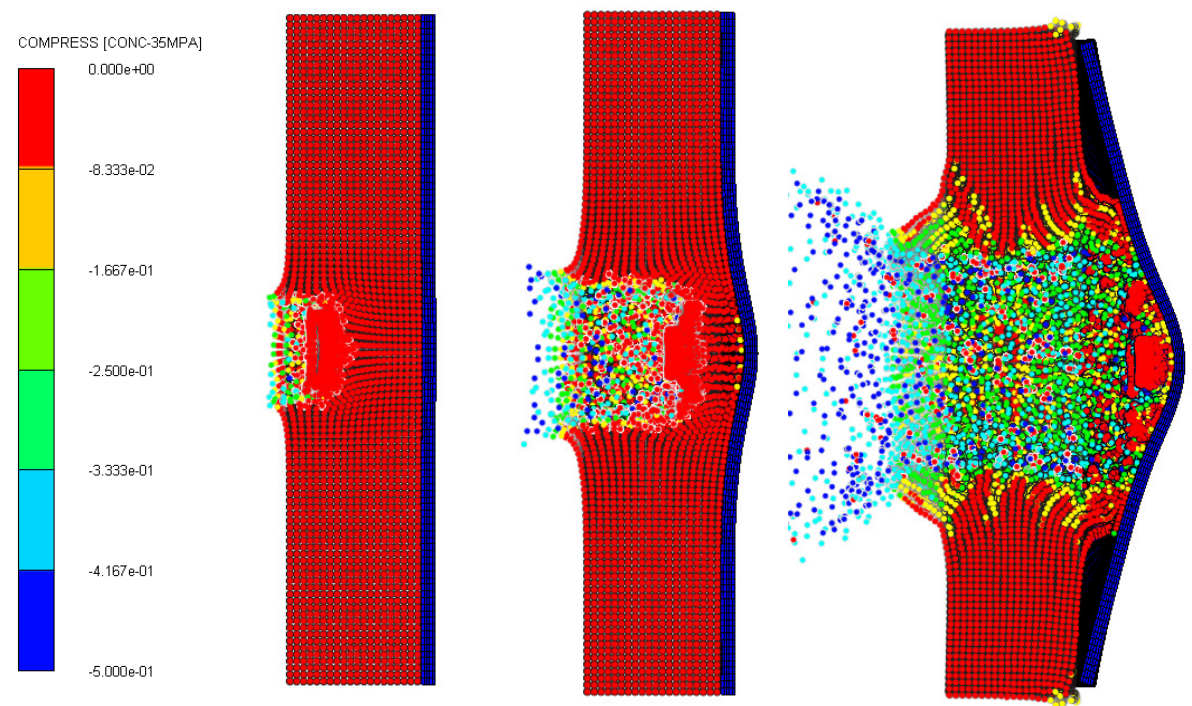

Figure 27: EFP penetration into $100 \mathrm{~mm}$ concrete core (no front steel plate) and changes in concrete material compression COMPRESS $=\ln \left(\rho / \rho_{0}\right)(0.06 \mathrm{~ms}, 0.15 \mathrm{~ms}, 0.80$ ms)

Despite initially having a slower rate of deceleration of the EFP velocity as compared to other SC barrier configurations with a front face plate (see Figure 30), analysis of the projectile velocity time history as presented in Figure 28(a) shows that the EFP is still effectively terminated by the SC barrier unit at about $0.8 \mathrm{~ms}$ after impact.

The graph in Figure 28(b) shows that the rear face steel plate would move away from the concrete core at an average velocity of $38 \mathrm{~m} / \mathrm{s}$ (at $t=0.8 \mathrm{~ms}$ ) after being hit by the EFP. 

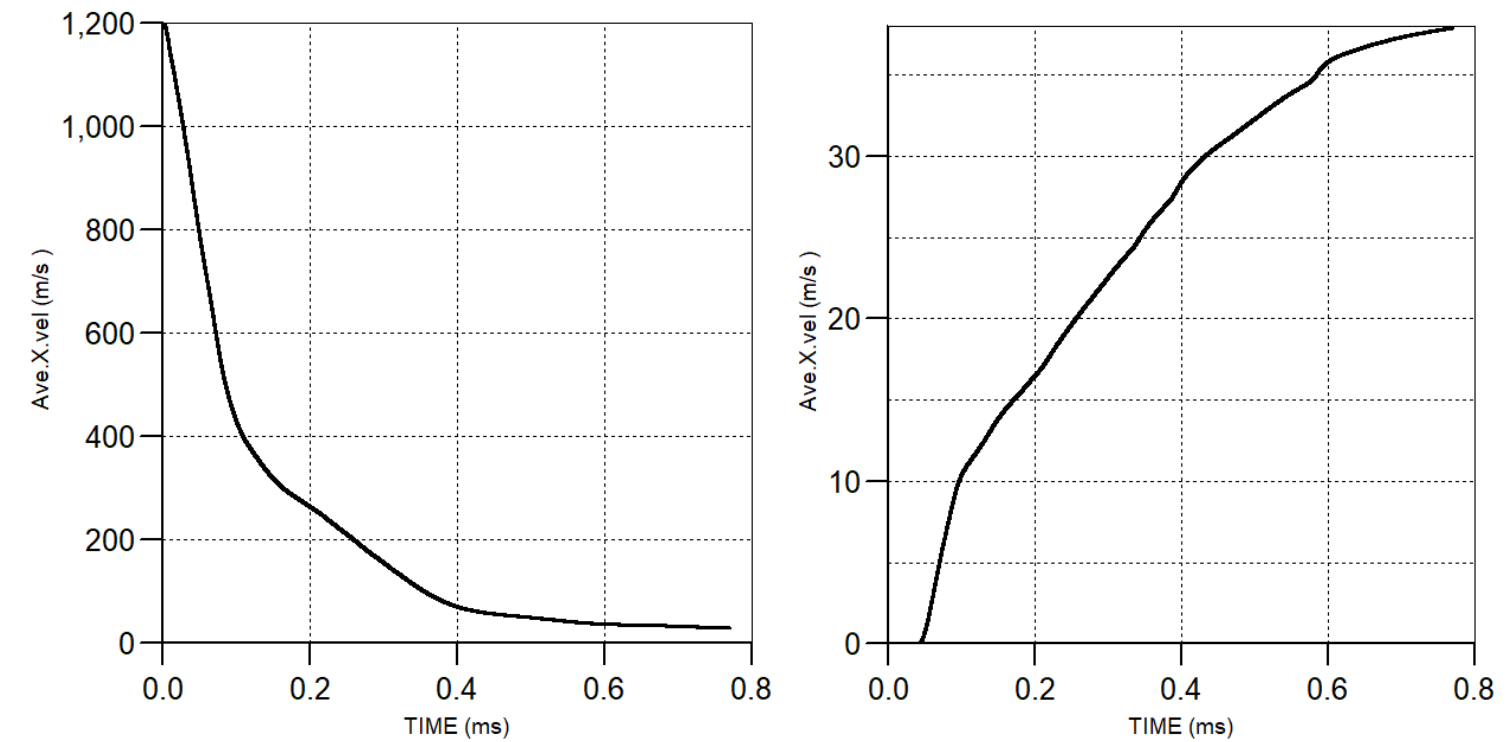

673

674

675

676

677

678

679

680

681

682

683

684

685

686

687

688

689

690

691
Figure 28: (a) evolution of the projectile velocity during penetration of $100 \mathrm{~mm}$ concrete panel (without front steel plate); (b) average velocities of rear steel plate in noncomposite SC blocks

\subsubsection{Optimisation of SC barrier configuration}

Based on the results of experimental and numerical studies presented above, a number of observations can be made to help for optimizing designs of the SC protective barriers. Comparison of the EFP deceleration curves in Figure 29 for several designs of steel-concretesteel protective units and a protective system based on spaced steel plates demonstrates the advantages of utilising the concrete infill between the steel plates for terminating hypervelocity impacts by EFPs. Depending on the thickness of the concrete core and the EFP impact velocity, the following mechanisms and phases of EFP deceleration have been identified:

(1) Phase 1 - Deceleration by the front face steel plate. A $9.5 \mathrm{~mm}$ thick steel plate provides deceleration to about $70 \%$ of the initial impact velocity of the EFP. It takes about $0.1 \mathrm{~ms}$ for the EFP to fully perforate the ruptured steel plate and exit into an air with a velocity of about $800 \mathrm{~m} / \mathrm{s}$ as shown in Figure 29 (Curve 1).

(2) Phase 2 - Deceleration by the front face steel plate - concrete interface. When the steel plate is backed by the concrete core, the rate of deceleration remains nearly 
constant as the EFP starts penetrating into the concrete core.

(3) Phase 3 - Deceleration by the concrete core. The onset and rate of concrete core penetration by the EFP is determined by the concrete core thickness. When the concrete thickness is comparable in size with the EFP major dimensions, the EFP is effectively constrained between the steel plates which results in an earlier onset of Phase 3 and higher deceleration rate (Curve 2 in Figure 29). When the concrete core is sufficiently thick to fully terminate the EFP (Curve 4 in Figure 29), the deceleration continues with an average rate of $330,000 \mathrm{~m} / \mathrm{s} / \mathrm{s}$ until the full stop of the EFP.

(4) Phase 4 - Deceleration by the rear face steel plate. The EFP - rear face steel plate interaction plays an important role for the SC protective units designed with the concrete core thickness that is not sufficient for full termination of the EFP within the concrete core. In this case, the EFP comes into contact with the rear face steel plate and the EFP and the rear steel plate start moving together. By this stage, the EFP velocity is not sufficient for perforating a $9.5 \mathrm{~mm}$ steel plate but it could cause large localised bulging deformations in the steel plate. 


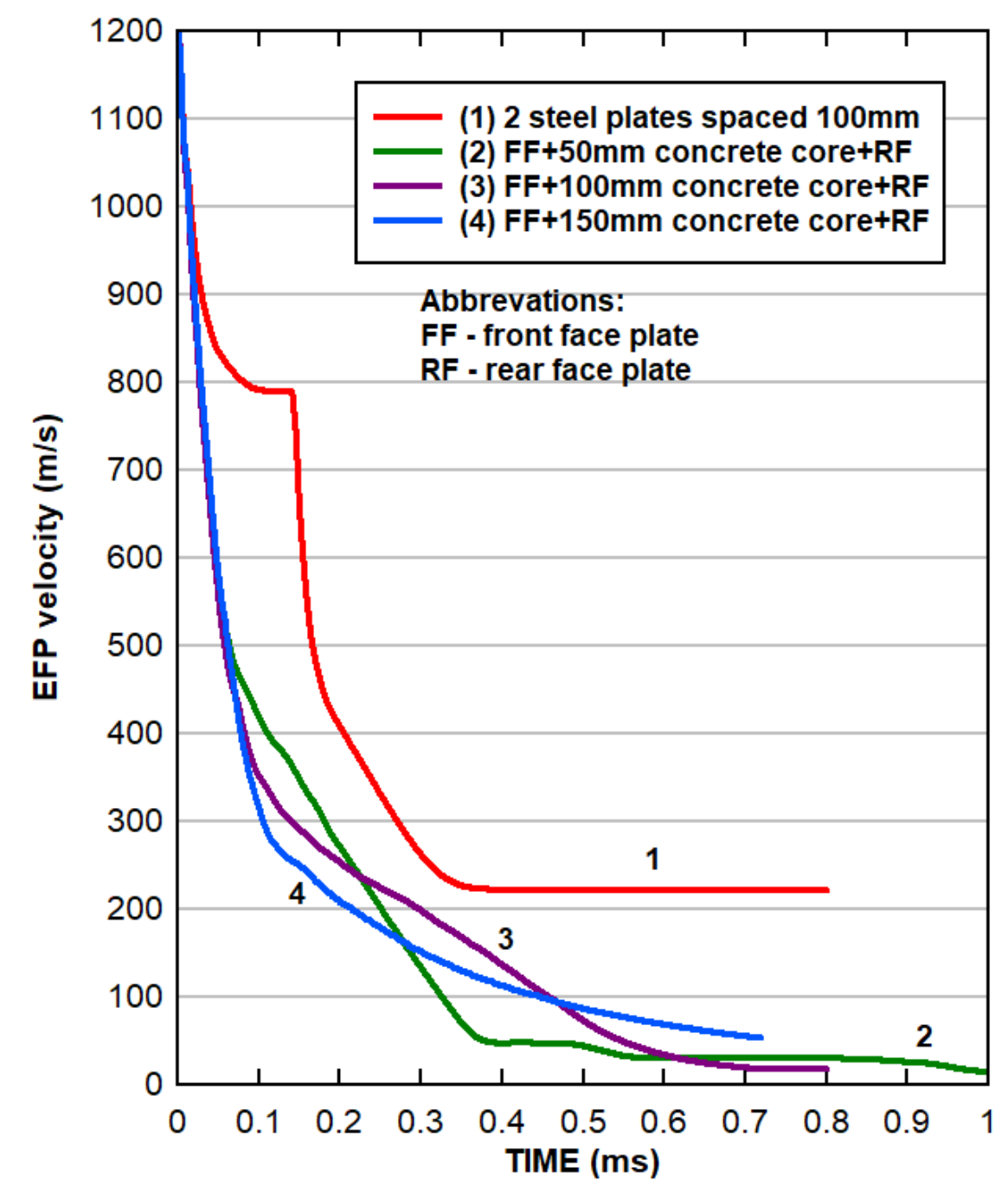

Figure 29: Comparison of EFP deceleration for SC block designs with 50, 100, and 150 mm concrete thicknesses

711 The optimal design of the SC barrier units should consider uncertainties associated with

712 the EFP calibres and their velocities. In the tests presented in this paper, a $100 \mathrm{~mm}$ calibre

713 EFP device was used. In real life scenarios, an EFP device could have a diameter up to 400

$714 \mathrm{~mm}$ and use thinner metal liners thus producing EFPs with much higher velocities and mass

715 that those considered in this study. Therefore, design of SC protective units should consider a

716 number of design parameters such as an aerial density required, type of infrastructure to be

717 protected, maximum EFP velocity, cost and availability of the materials, and ease of 718 installation. 
Table 8 summarises the ballistic performance of the SC units analysed in this study. Based

720 on an aerial density as an objective function for optimising SC protective units, the spaced

721 steel plate armour system appears to be the most economical due to its lowest aerial density.

722 On the other hand, terminating larger diameter EFPs flying with higher velocities than that

723 considered in this study may require increasing the number of steel plates to 5 or more which

724 may not be practical and could increase the aerial density of the armour to the levels

725 comparable to the steel-concrete protective systems.

726

727 Table 8: Summary of ballistic performance of SC protective units

\begin{tabular}{|c|c|c|c|c|c|}
\hline $\begin{array}{c}\text { SC block } \\
\text { configurations }\end{array}$ & $\begin{array}{c}\text { Aerial } \\
\text { density } \\
{\left[\mathrm{kg} / \mathrm{m}^{2}\right]}\end{array}$ & $\begin{array}{c}\text { Ballistic } \\
\text { performance }\end{array}$ & $\begin{array}{c}\text { EFP velocity } \\
\text { after barrier } \\
\text { penetration } \\
{[\mathrm{m} / \mathrm{s}]}\end{array}$ & $\begin{array}{c}\text { Average } \\
\text { velocity of } \\
\text { front face } \\
\text { plate }[\mathrm{m} / \mathrm{s}]\end{array}$ & $\begin{array}{c}\text { Average } \\
\text { velocity of } \\
\text { rear face } \\
\text { plate }[\mathrm{m} / \mathrm{s}]\end{array}$ \\
\hline 2 steel plates ${ }^{*}$ & 149.1 & Perforation & 210 & - & - \\
\hline 3 steel plates ${ }^{*}$ & 223.7 & $\begin{array}{c}\text { EFP } \\
\text { termination by } \\
3^{\text {rd }} \text { plate }\end{array}$ & 0.0 & - & - \\
\hline $\begin{array}{l}2 \text { plates }^{*}+150 \mathrm{~mm} \\
\text { concrete core }\end{array}$ & 509.2 & $\begin{array}{c}\text { EFP } \\
\text { termination by } \\
\text { concrete }\end{array}$ & 0.0 & 7.0 & 17.0 \\
\hline $\begin{array}{l}2 \text { plates }^{*}+100 \mathrm{~mm} \\
\text { concrete core }\end{array}$ & 389.2 & $\begin{array}{c}\text { EFP } \\
\text { termination by } \\
\text { concrete and } \\
\text { rear face plate }\end{array}$ & 0.0 & 7.0 & 27.0 \\
\hline $\begin{array}{l}2 \text { plates }^{*}+50 \mathrm{~mm} \\
\text { concrete core }\end{array}$ & 269.2 & $\begin{array}{c}\text { EFP } \\
\text { termination by } \\
\text { concrete and } \\
\text { rear face plate }\end{array}$ & 0.0 & 6.0 & 34.0 \\
\hline $\begin{array}{c}100 \mathrm{~mm} \text { concrete core }+ \\
1 \text { plate }^{*}\end{array}$ & 314.6 & $\begin{array}{l}\text { EFP erosion, } \\
\text { termination by } \\
\text { concrete and } \\
\text { rear face plate }\end{array}$ & 0.0 & No plate & 38.0 \\
\hline
\end{tabular}

* Note: all steel plates in this table are $9.5 \mathrm{~mm}$ high-strength steel plates

730 As evidenced by extensive experimental and numerical results presented in this paper, the

731 optimal design for the SC protective units that delivers reliable terminal ballistic performance

732 appears to be related to providing sufficient thickness of a concrete infill between the steel

733 plates that could decelerate and terminate the EFP within the concrete core and prevent the 
734 EFP from coming into contact with the rear steel plate. Generally, high-velocity outward movement of the rear face steel plate should be prevented in the design of SC protective systems to avoid injuries to personnel or damage to infrastructure protected by the SC units. The experimental results presented in Section 4 have proven the effectiveness of reinforcing the concrete core with steel meshes and using high-strength through bolts for minimising outward motion of the face plates.

740 Designing the SC barriers to terminate the EFP within the concrete core would also

741 provide an additional safety margin where the rear steel plate is utilised as the last line of 742 defence should the front face steel plate and the concrete core are fully penetrated by the 743 EFP. Based on this design philosophy, a SC unit with a $150 \mathrm{~mm}$ thick concrete core appears 744 to be the optimal design for ballistic protection from an EFP attack with a velocity of 1200 $745 \mathrm{~m} / \mathrm{s}$.

746 Additional mass minimization could be achieved by utilising the SC units that do not 747 include a front face steel plate. This design would rely only on the concrete resistance to 748 decelerate the EFP and the rear face steel plate as a liner to prevent full penetration of the SC 749 barrier. The deceleration curves for the $100 \mathrm{~mm}$ SC blocks with and without front steel plates 750 are compared in Figure 30. It can be inferred from the graph that without the front face steel 751 plate the EFP is decelerated by the concrete core less effectively and comes into contact with 752 the rear face steel plate earlier than that for the other designs. Significant disadvantage of this 753 SC protective unit design is highly hazardous concrete fragments produced by the shattered 754 concrete core that fly outward with very high velocity. This failure mode of the SC units 755 without the front steel plate makes this design generally not satisfactory for protecting personnel and infrastructure from the EFPs.

The concrete core sandwiched in between two steel face plates provides the most significant contribution to the aerial density of the SC protective units. Mass of the concrete 
core could be substantially reduced by using lightweight concrete with density $1450 \mathrm{~kg} / \mathrm{m}^{3}$ as described by Sohel and Liew [17] in application to the SC sandwich slabs subjected to impact

761 load. Effectiveness of adding steel fibres into the concrete core to reduce brittleness of 762 concrete due to high-speed impact loads is an additional direction for future research into 763 optimisation of the SC barrier units.

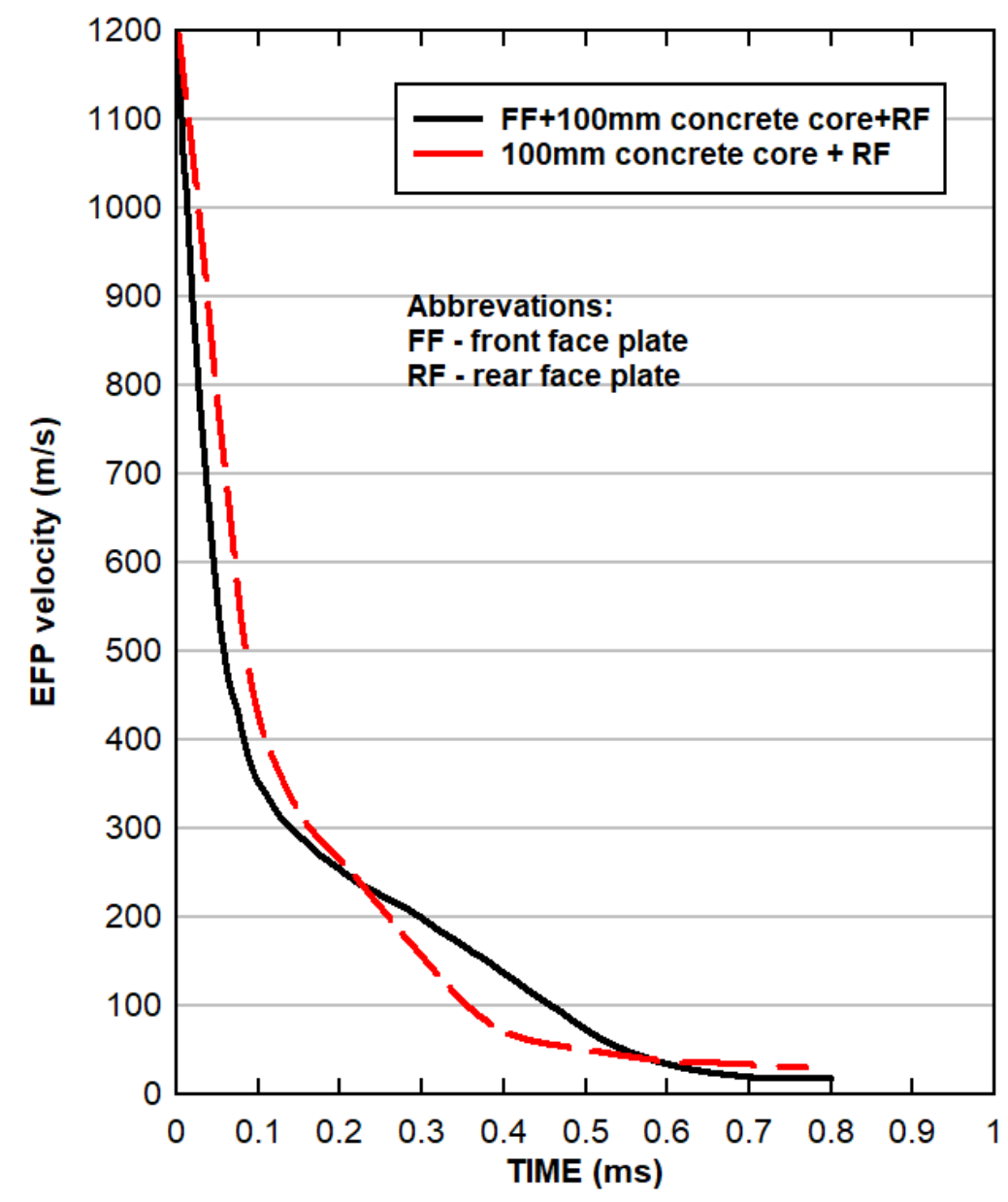
and without front face steel plate

\section{CONCLUSIONS}

769 Use of steel-concrete systems is common for protective structural systems requiring a

770 high level of protection from various forms of IEDs. No work has been done up until now to understand the response of steel-concrete sandwich systems to hypervelocity impacts 
772 by EFPs. EFP is one of the latest and most destructive warheads and IEDs for which no 773 adequate protection has been developed so far. Relatively little research has been 774 published on defeating this threat.

775 Nine steel-concrete target units of finite sizes with different grades of high-strength 776 steel plates, concrete core strength and degree of composite action were subjected to 777 hypervelocity impacts to evaluate their capabilities in terminating EFPs. The experimental results confirmed the high destructive capacity of EFPs and their ability to demolish steel-concrete elements of substantial sizes. The following specific conclusions can be drawn based on the hypervelocity impact tests of the SC protective systems:

781 1. The steel face plates in the SC protective units acquire sufficient momentum to fly away from the concrete core and become secondary projectiles after being struck by the EFP.

2. Steel face plates with a yield strength varying from $600 \mathrm{MPa}$ to $1600 \mathrm{MPa}$ and variable hardness were used in the tests. The steels with higher strength and/or hardness did not show an appreciable difference in the dimensions of the entry hole or the overall terminal ballistic performance of the SC systems to the EFP impacts.

3. SC protective units were designed with nominally normal strength concrete (NSC) and high-strength concrete (HSC) cores. There was no appreciable difference in the penetration performance of the sandwich units with NSC and HSC unreinforced cores subjected to hypervelocity EFP impacts.

4. To maintain the integrity of the SC sandwich units, the use of high-strength steel through bolts was found to be a most effective means to resist the outward accelerated motion of the steel face plates. 
5. It has been verified experimentally that reinforcing the concrete core with steel meshes connected with shear links is an effective means for maintaining sufficient integrity of the concrete core.

6. EFP simulations using hydrocodes and experimentally validated numerical models provided important insights into the interaction of steel plates and a concrete core

7. Numerical simulations have demonstrated an important contribution of the rear face plate for catching EFPs after their penetration through the concrete core for relatively thin SC unit designs. Minimum threshold for terminating the EFPs by the concrete core appears to be around $150 \mathrm{~mm}$ thick concrete core for a $1200 \mathrm{~m} / \mathrm{s}$ EFP impact. For higher

Although all steel-concrete protective systems were substantially damaged by the

809 EFPs, the important outcome of this work is that the steel-concrete protective systems are

810 capable of providing effective protection against an EFP threat. In all tests, the rear steel

811 plate remained intact indicating that a combination of a steel plate and a concrete layer of 812 an optimal thickness may provide effective protection against hypervelocity impacts by

813 EFPs. Further studies are required to evaluate the effects of hypervelocity impacts on 814 common steel and concrete structures, and methods of protection from this type of threat.

\section{ACKNOWLEDGEMENTS}

817 The support of Mr Arran Gordon of Havoc Industries with carrying out the blast trials is 818 gratefully acknowledged. Our thanks are due to Mr Alan Grant (UOW), Mr Cameron 
819 Nielson (UOW), and $\mathrm{Mr}$ Fernando Escribano (UOW) for their assistance with

manufacturing test specimens and conducting the tests.

821

822

823

824

825

826

827

828

829

830

831

832

833

834

835

836

837

838

839

840

841

842

843

844

845

846

847

848

849

850

851

852

853

854

855

856

857

858

859

860

861

862

863

864

865

\section{REFERENCES}

[1] Walters WP and Zukas JA, Fundamentals of shaped charges. New York: John Wiley and Sons, 1989.

[2] Hazell P, Armour. Boca Raton, FL: CRC Press, 2015.

[3] $\mathrm{Wu}$ J, Liu J, and Du Y. Experimental and numerical study on the flight and penetration properties of explosively-formed projectile. International Journal of Impact Engineering. 2007, 34:1147-62.

[4] Liu J., Long Y, Ji C, Liu Q, Zhong M, Ge S. Ballistic performance study on the composite structures of multi-layered targets subjected to high velocity impact by copper EFP. Composite Structures. 2018, 184:484-96.

[5] Hu F, Wu H, Fang Q, Liu J, Liang B, Kong XZ. Impact performance of explosively formed projectile (EFP) into concrete targets. International Journal of Impact Engineering. 2017, 109:150-66.

[6] Zukas JA and Walters WP. Explosive effects and applications. New York: Springer, 2003.

[7] Bookout L, Baird J. Impact effects of explosively formed projectiles on normal and high strength concrete. In: AIP Conference Proceedings 1426, 2012, vol. 52.

[8] Bruhl JC, Varma AH, Johnson WH. Design of composite SC walls to prevent perforation from missile impact. International Journal of Impact Engineering. 2015, 75:75-87.

[9] Hashimoto J, Takiguchi K, Nishimura K, Matsuzawa K, Matsuzawa M, Ohashi Y, Kojima I, Kojima H. Experimental study on behavior of rc panels covered with steel plates subjected to missile impact, 18th International Conference on Structure Mechanics in Reactor Technology (SMiRT 18) Beijing, China, August 7-12, 2005 SMiRT18-J05-4.

[10] Remennikov AM and Uy B. Explosive testing and modelling of square tubular steel members for near-field detonations. Journal of Constructional Steel Research. 2014, 101:290-303.

[11] Remennikov AM, Kong SY, Uy, B. The response of axially restrained on- composite steel-concrete-steel sandwich panels due to large impact loading, Engineering Structures, 2013, 49:806-18.

[12] Ngo T, Mohotti D, Remennikov A, Uy B (2015) Numerical simulations of response of tubular steel beams to close-range explosions, Journal of Constructional Steel Research. 2015, 105:151-63.

[13] Bisalloy Steels. Bissalloy Technical Manual. http://www.steelcutting.com.au/SiteFiles/ steelcuttingcomau/Bisalloy-Bisplate-Technical-Manual.pdf (accessed 12 December 2017).

[14] Autodyn, Autodyn User's Manual, Release 17.1, 2016.

[15] X. Quan, N. K. Birnbaum, M. S. Cowler, B. I. Gerber, and C. J. Hayhurst, "Numerical Simulation Of Structural Deformation Under Shock And Impact Loads Using A Coupled Multi-Solver Approach," in 5th Asia-Pacific Conference on Shock and Impact Loads on Structures, Hunan, China, 2003, pp. 12-14.

[16] Herrmann W. Constitutive Equation for the Dynamic Compaction of Ductile Porous Materials. Journal of Applied Physics. 1969, 40:2490-99.

[17] Sohel, K. M. A., \& Liew, J. Y. R. (2014). Behavior of steel-concrete-steel sandwich 
slabs subject to impact load. Journal of Constructional Steel Research, 100, 163-175. DOI: 10.1016/j.jcsr.2014.04.018. 